\title{
What processes control the chemical compositions of arc front stratovolcanoes?
}

\section{Citation}

Turner, Stephen J., and Charles H. Langmuir. 2015. “What Processes Control the Chemical Compositions of Arc Front Stratovolcanoes?" Geochem. Geophys. Geosyst. 16 (6) (June): 18651893. doi:10.1002/2014gc005633.

\section{Published Version}

doi:10.1002/2014GC005633

\section{Permanent link}

http://nrs.harvard.edu/urn-3:HUL.InstRepos:30367419

\section{Terms of Use}

This article was downloaded from Harvard University's DASH repository, and is made available under the terms and conditions applicable to Other Posted Material, as set forth at http:// nrs.harvard.edu/urn-3:HUL.InstRepos:dash.current.terms-of-use\#LAA

\section{Share Your Story}

The Harvard community has made this article openly available.

Please share how this access benefits you. Submit a story.

\section{Accessibility}




\section{Geochemistry, Geophysics, Geosystems}

\section{RESEARCH ARTICLE \\ 10.1002/2014GC005633 \\ What processes control the chemical compositions of arc front stratovolcanoes?}

Key Points:

- Arcs have clear global systematics that should be accounted for by models

- Either wedge or slab thermal structure can account for global chemical trends.

- Arc front and rear-arc ${ }^{143} \mathrm{Nd} /{ }^{144} \mathrm{Nd}$ correlate, indicating wedge heterogeneity

Supporting Information: - Supporting Information S1 - Supporting Information S2

- Data Set S1

- Software S1

Correspondence to:

S. J. Turner,

sturner@fas.harvard.edu

\section{Citation:}

Turner, S. J., and C. H. Langmuir (2015), What processes control the chemical compositions of arc front stratovolcanoes?, Geochem. Geophys. Geosyst., 16, 1865-1893, doi:10.1002/ 2014GC005633.

Received 26 OCT 2014 Accepted 30 MAR 2015 Accepted article online 7 APR 2015 Published online 19 JUN 2015

\author{
Stephen J. Turner ${ }^{1}$ and Charles H. Langmuir ${ }^{1}$ \\ ${ }^{1}$ Department of Earth and Planetary Sciences, Harvard University, Cambridge, Massachusetts, USA
}

\begin{abstract}
Arc front stratovolcanoes have global chemical systematics that constrain processes at convergent margins. Positive correlations exist for arc averages among "fluid mobile," "high field strength," and "large ion lithophile" elements. ${ }^{143} \mathrm{Nd} /{ }^{144} \mathrm{Nd}$ and ${ }^{87} \mathrm{Sr} /{ }^{86} \mathrm{Sr}$ from rear-arc lavas lacking subduction signature align with the oceanic "mantle array," and correlate with arc front ${ }^{143} \mathrm{Nd} /{ }^{144} \mathrm{Nd}$. Most chemical parameters (but not isotopes) also correlate well with crustal thickness and slightly less well with the slab thermal parameter, but not with the depth of the slab nor model slab surface temperatures. Successful models of arc volcanism should account for these global regularities. Two distinct models can quantitatively account for the observationsdifferent extents of melting of the mantle wedge caused by variations in wedge thermal structure, or varying contributions from the subducting slab owing to variations in the slab thermal structure. Both successful model scenarios require a significant flux of melted ocean crust to the mantle source of all volcanic arcs. The wedge melting model has constant contributions from ocean crust, sediment, and mantle wedge to lavas globally, while the slab model varies slab contributions with slab temperature. The wedge melting model fit improves by incorporating convergence rate and slab dip, which should affect the wedge thermal structure; the slab model is not supported by a similar analysis. The wedge model also more easily accommodates the isotope data. The two models predict different primary $\mathrm{H}_{2} \mathrm{O}$ contents, with large variations in $\mathrm{H}_{2} \mathrm{O}$ for the wedge model, and relatively constant $\mathrm{H}_{2} \mathrm{O}$ for the slab model. An evaluation of the effects of varying sediment compositions on arc lavas will benefit from considering the very different consequences of the two models.
\end{abstract}

\section{Introduction}

Subduction zone processes regulate fluxes among many of Earth's geochemical reservoirs. Subducted oceanic crust is recycled back into the mantle, where metamorphism of serpentinized peridotite, basaltic crust, and sediment causes addition of aqueous fluids, hydrous melts, or supercritical liquids to the mantle wedge [e.g., Morris and Tera, 1989; Miller et al., 1994; Elliott et al., 1997; Spandler and Pirard, 2013]. Melting within the wedge results from depression of the solidus by this hydrous slab component, with possible contributions from decompression of peridotite [Grove et al., 2006; Cameron et al., 2003]. Melts produced in the wedge may ascend rapidly to the surface and undergo closed system crystal fractionation, or could undergo a combination of fractionation and assimilation of crustal material [DePaolo, 1981]. This complex series of events results in the variety of arc magma compositions that add to the crust, and also transfers volatiles to surface reservoirs. Because subduction zones influence the chemical characteristics of multiple earth reservoirs-mantle, continental crust, and atmosphere-it is important to determine the relative contributions of the various sources, physical variables, and processes that give rise to global variations in arc magma chemistry.

In order to further constrain the processes and fluxes operating in subduction zone settings, Turner and Langmuir [2015, hereafter referred to as TL2015a] provide a new, global database of major element, trace element, and $\mathrm{Sr}, \mathrm{Nd}, \mathrm{Pb}$, and $\mathrm{Hf}$ isotopic compositions of arc front stratovolcanoes, normalized to constant $\mathrm{MgO}$ content or $\mathrm{Mg \#}$. That study confirms previously observed correlations among averaged, normalized major and trace element compositions of magmas erupted at volcanic fronts worldwide [Plank and Langmuir, 1988, 1993], and adds new first-order observations of the chemical systematics of arc front stratovolcanoes (Figure 1). These findings include global correlations among most incompatible elements, with up to a factor of five variation in elemental abundances. Global correlations among incompatible elements are not limited to within traditional groupings, but include elements from "large ion lithophile," "fluid mobile," and "high field strength" element groups. In contrast to the large ranges in concentrations, most incompatible trace element ratios vary by less than $50 \%$. While the overall variability of these ratios is limited, certain 


\section{QAGU Geochemistry, Geophysics, Geosystems}
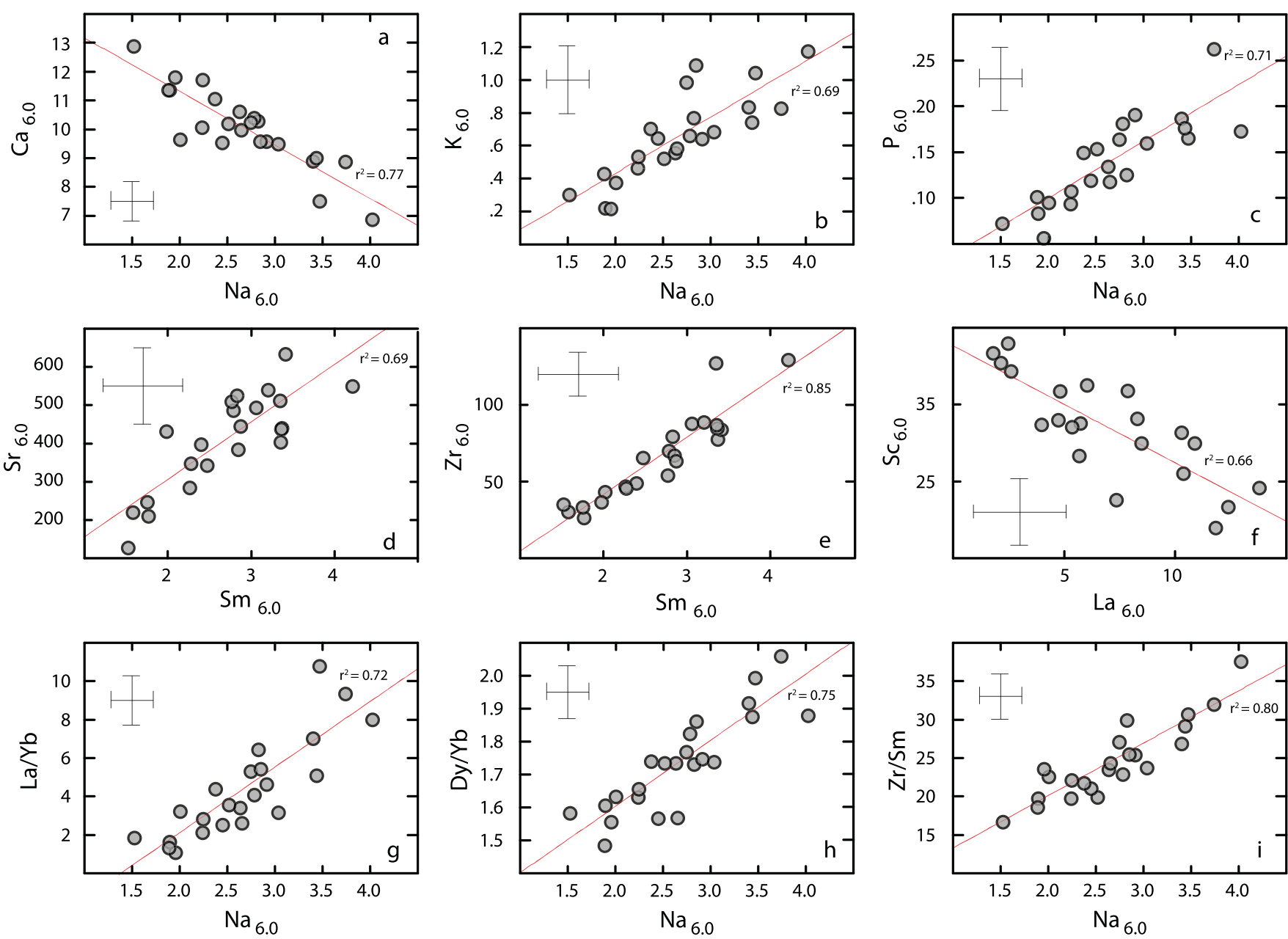

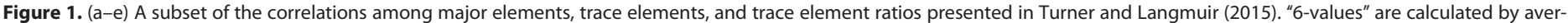

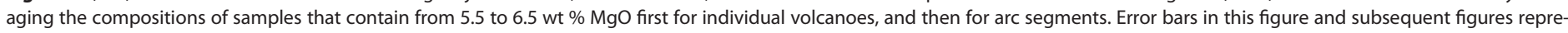
sent the average standard deviation for volcano averages within arc segments. Positive correlations exist among nearly all incompatible elements, regardless of traditional element

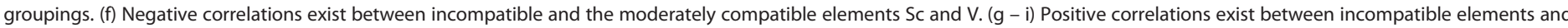

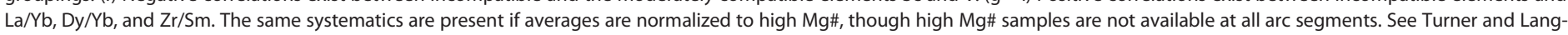
muir (2015) for a full discussion of the calculation and the first-order assessment of global systematics.

ratios, such as $\mathrm{Zr} / \mathrm{Sm}$ and $\mathrm{Dy} / \mathrm{Yb}$, increase regularly with incompatible element concentrations. The moderately compatible elements $\mathrm{Ca}, \mathrm{Sc}$, and $\mathrm{V}$ decrease with increasing incompatible element concentrations. Concentrations of heavy rare earth elements (HREE) do not correlate with incompatible element concentrations, and vary by only $\sim 50 \%$. These relationships are the global first-order systematics of average arc volcano compositions. Models of arc volcanism should account for these observations in a coherent, internally consistent framework.

These chemical parameters also all correlate with the thickness of the overlying arc crust. While this might seem to indicate an important role for crustal contamination in creating the global relationships, the analysis of TL2015a demonstrated that the global correlations in average arc magma chemistry are most likely primary in nature, rather than the result of processes within the overriding plate. This paper builds upon that analysis by incorporating a larger set of physical subduction parameters, isotopic compositions, and an additional global database of rear-arc volcanism, in order to assess the relative contributions of slab and mantle processes to the global chemical diversity of volcanic arcs. The goal of this paper is to evaluate firstorder models that may account for differences and correlations among average arc compositions worldwide.

This paper and TL2015a use arc average compositions that are normalized to a constant MgO and computed with a double averaging step, first determining individual volcano averages, and then averaging the 
volcanoes. The aim is to compare compositional variation with global subduction parameters, such as convergence rate and slab age, which often have limited variability within individual arcs. The fact that there are such clear relationships among arc averaged chemical variables and between those variables and subduction parameters suggests that an arc averaging approach has value, removing the inevitable local complexities within individual volcanic edifices. Variations within individual volcanoes, as well as among volcanoes within particular arcs, also contain information that is pertinent to the questions considered here, but discussion of local chemical variations will be left to future work. The relationships discussed in this paper provide a useful framework for detailed studies of intra-arc variability. Turner et al. (in preparation, 2015), for example, evaluates intra-arc chemical variability of the Chilean Southern Volcanic Zone in the context of the global relationships discussed here.

\section{Results}

In addition to the global chemical systematics shown in Figure 1 and demonstrated in TL2015a, this study incorporates $\mathrm{Sr}, \mathrm{Nd}, \mathrm{Pb}$, and $\mathrm{Hf}$ isotopic data as well as a database of samples from rear-arc settings. These combined data provide more comprehensive constraints on elemental fluxes through global subduction zones. Details about specific data points and variance of data within arcs and volcanoes can be found in TL2015a. Error bars in most figures represent the average standard deviation for global arcs, as the emphasis here is on explanations of the global trends rather than a discussion of the substantial variability that occurs within volcanoes from a single arc.

\subsection{Rear-Arc Database}

Determining the composition of the wedge prior to enrichment by slab fluxes (the "ambient mantle wedge" composition) is a necessary first step toward constraining the fluxes of material from the slab to the mantle and crust. To explore variations in mantle wedge compositions, a database of samples from behind the volcanic front was compiled for arc segments with adequate data availability, and is available in the supporting information. These samples are referred to collectively as "rear-arc." In continental rear-arc settings many element ratios and concentrations are affected by low degrees of melting, and thus may not represent source compositions. The Nd and Sr isotopic compositions of rear-arc magmas, however, are less likely to be fractionated by melting processes, and should match their source compositions. To minimize the effects of slab contributions on the selected rear-arc samples, compositions were screened based on the $\mathrm{Th} / \mathrm{Nb}$ ratio. Both Th and $\mathrm{Nb}$ have bulk partition coefficients $\ll 0.01$, so the Th/Nb ratio is little affected even by very low degrees of melting. The strong negative $\mathrm{Nb}$ anomalies and the notable enrichment of Th found in nearly all arc front samples indicate that the Th/Nb ratio is particularly sensitive to slab addition [Elliott et al., 1997]. For the rear-arc database, only samples with $\mathrm{Th} / \mathrm{Nb}<0.14$ were included. Only $1 \%$ of all arc front samples for which both $\mathrm{Th}$ and $\mathrm{Nb}$ are measured have $\mathrm{Th} / \mathrm{Nb}<0.14$, while virtually all oceanic basalts have $\mathrm{Th} / \mathrm{Nb}$ values below this threshold. This filtered data set thus provides an estimate of the ambient mantle wedge isotopic compositions with minimal subduction influence for the 11 segments that are included.

Some of the rear-arc lavas have high $\mathrm{Nb}$ concentrations, but even high $\mathrm{Nb}$ lavas can be effectively screened for slab addition using the Th/Nb ratio. Samples from the volcanic front of Costa Rica, for example, have high $\mathrm{Nb}$ but also high $\mathrm{Th} / \mathrm{Nb}$.

There are legitimate questions about the comparability of rear-arc data from different regions. Some compositions come from back-arc basins, where there are large magmatic fluxes. In these cases, influx of mantle that is not beneath the current arc is possible. For the Central Aleutians, data from the Pribilof Islands are used to represent the unmodified ambient mantle. These islands are $\sim 420 \mathrm{~km}$ from the arc front, much farther than rear-arc volcanics used in other arc segments, and could possibly be sampling a mantle domain that is distinct from the ambient sub-arc mantle. Despite these limitations, all of the rear-arc samples have similar relationships to the samples from the arc front, and therefore provide a useful comparison to volcanic front compositions.

\subsection{Isotope Data}

The database of TL2015a provided average arc segment values for ${ }^{87} \mathrm{Sr} /{ }^{86} \mathrm{Sr},{ }^{143} \mathrm{Nd} /{ }^{144} \mathrm{Nd},{ }^{176} \mathrm{Hf} /{ }^{177} \mathrm{Hf}$, ${ }^{206} \mathrm{~Pb} /{ }^{204} \mathrm{~Pb},{ }^{207} \mathrm{~Pb} /{ }^{204} \mathrm{~Pb}$, and ${ }^{208} \mathrm{~Pb} /{ }^{204} \mathrm{~Pb}$, but the paper limited discussion to major and trace element compositions. Average isotope ratios were calculated via the same method as trace element ratios. After 

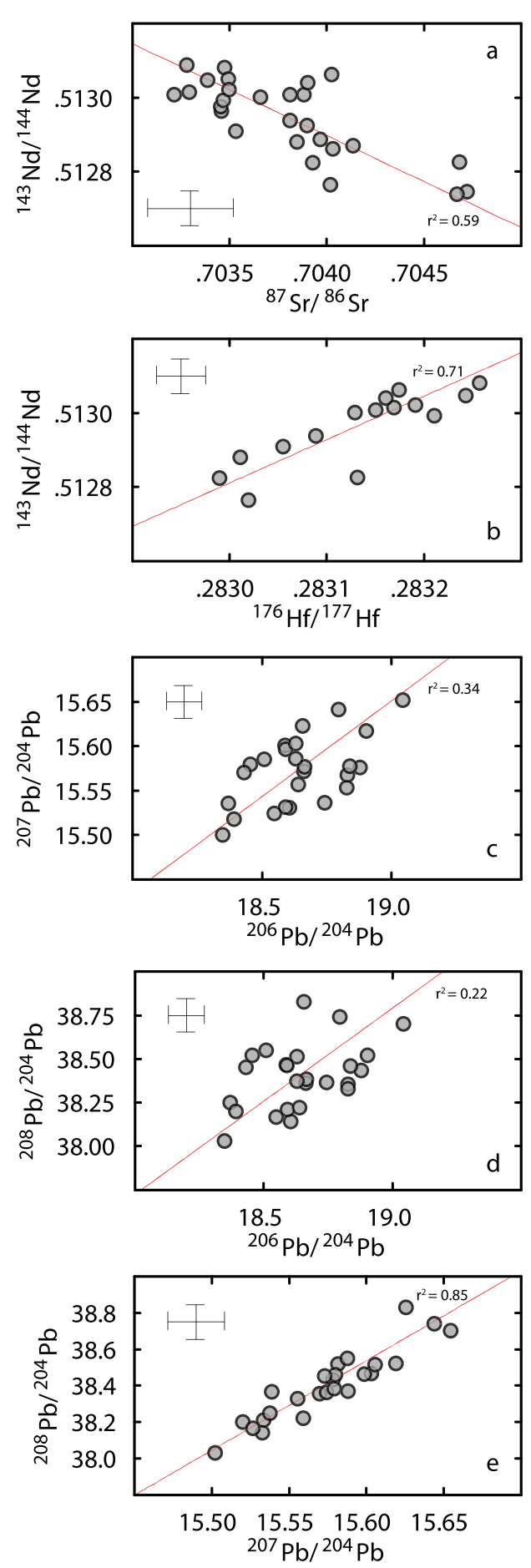

Figure 2. Relationships among average arc front $\mathrm{Nd}, \mathrm{Sr}, \mathrm{Hf}$, and $\mathrm{Pb}$ isotopes for average arc compositions. (a) ${ }^{143} \mathrm{Nd} /{ }^{144} \mathrm{Nd}$ correlates negatively with ${ }^{87} \mathrm{Sr} /{ }^{86} \mathrm{Sr}$ and (b) positively with ${ }^{176} \mathrm{Hf} /{ }^{177} \mathrm{Hf} .{ }^{206} \mathrm{~Pb} /{ }^{204} \mathrm{~Pb}$ has a weak positive correlation with ${ }^{207} \mathrm{~Pb} /{ }^{204} \mathrm{~Pb}$ and ${ }^{208} \mathrm{~Pb} /{ }^{204} \mathrm{~Pb}$, (c-e) while

${ }^{207} \mathrm{~Pb} /{ }^{204} \mathrm{~Pb}$ and ${ }^{208} \mathrm{~Pb} /{ }^{204} \mathrm{~Pb}$ correlate strongly. These relationships among $\mathrm{Pb}$ isotopes likely reflect $\mathrm{Pb}$ isotope signatures dominated by the subducting slab, as alteration of the slab on the seafloor will affect ${ }^{206} \mathrm{~Pb} /{ }^{204} \mathrm{~Pb}$ to a greater degree than ${ }^{207} \mathrm{~Pb} /{ }^{204} \mathrm{~Pb}$ or ${ }^{208} \mathrm{~Pb} /{ }^{204} \mathrm{~Pb}$. Errors bars reflect variation within volcanoes from a single arc as in Figure 1. removing samples with large $\mathrm{Eu}$ anomalies, $\mathrm{MgO}$ below 4 wt \%, or $\mathrm{MgO}$ above $12 \mathrm{wt} \%$, compositions were first averaged within volcanoes, and then within segments (see TL2015a for details of data screening). Arcs that are influenced by nearby hot spots have an additional component that is not relevant to subduction parameters. Because the aim here is to assess the role of subduction parameters, arcs with nearby hot spot tracks and/or seismically imaged deep mantle plumes are not included in the following discussion-Southern Costa Rica, Northern Tonga, and the Aeolian [Gazel et al., 2011; Falloon et al., 2007; Montelli et al., 2006]. Northern Chile/Peru is also excluded from this discussion, as magmas erupted in this region may be uniquely overprinted during transit through the $70 \mathrm{~km}$ thick continental crust of the Central Andes.

For global arcs, ${ }^{143} \mathrm{Nd} /{ }^{144} \mathrm{Nd}$ correlates well with ${ }^{87} \mathrm{Sr} /{ }^{86} \mathrm{Sr} \quad\left(r^{2}=0.59\right.$, Figure 2a), strongly with ${ }^{176} \mathrm{Hf} /{ }^{177} \mathrm{Hf}\left(r^{2}=0.71\right.$, Figure $\left.2 b\right)$, and weakly with ${ }^{208} \mathrm{~Pb} /{ }^{204} \mathrm{~Pb}$ and ${ }^{207} \mathrm{~Pb} /{ }^{204} \mathrm{~Pb}\left(r^{2}=0.45, r^{2}=0.40\right)$. There is no correlation between ${ }^{143} \mathrm{Nd} /{ }^{144} \mathrm{Nd}$ and ${ }^{206} \mathrm{~Pb} /{ }^{204} \mathrm{~Pb}$. Among $\mathrm{Pb}$ isotopes, there is a weak correlation between ${ }^{206} \mathrm{~Pb} /{ }^{204} \mathrm{~Pb}$ and ${ }^{207} \mathrm{~Pb} /{ }^{204} \mathrm{~Pb}$ $\left(r^{2}=0.34\right.$, Figure $\left.2 \mathrm{c}\right)$ and a very weak correlation between ${ }^{206} \mathrm{~Pb} /{ }^{204} \mathrm{~Pb}$ and ${ }^{208} \mathrm{~Pb} /{ }^{204} \mathrm{~Pb}\left(r^{2}=0.22\right.$, Figure $2 \mathrm{~d}$ ). A notably strong linear correlation, with $r^{2}=0.85$, is present between ${ }^{207} \mathrm{~Pb} /{ }^{204} \mathrm{~Pb}$ and ${ }^{208} \mathrm{~Pb} /{ }^{204} \mathrm{~Pb}$ (Figure 2e). Because a large portion of the $\mathrm{Pb}$ contents of arc front magmas are slab derived [Kay, 1980], the weaker correlations with ${ }^{206} \mathrm{~Pb} /{ }^{204} \mathrm{~Pb}$ as compared to other $\mathrm{Pb}$ isotopes may be accounted for by the varying $\mathrm{Pb}$ isotope compositions of subducting sediments and alteration processes in the slab prior to subduction, as ${ }^{206} \mathrm{~Pb} /{ }^{204} \mathrm{~Pb}$ can be affected by $\mathrm{U}$ enrichment on relatively short time scales [e.g., Kelley et al., 2005].

High ${ }^{143} \mathrm{Nd} /{ }^{144} \mathrm{Nd}$ values tend to correspond to low $\mathrm{Nd}_{6.0}$ values, though this relationship does not hold for Ryukyu, the Aegean, and Central Honshu, which have the lowest average ${ }^{143} \mathrm{Nd} /{ }^{144} \mathrm{Nd}$ but low to moderate $\mathrm{Nd}$ abundances (Figure 3a). ${ }^{176} \mathrm{Hf} /{ }^{177} \mathrm{Hf}$ values correlate more strongly with some 6-values, but this is most likely due to the lack of ${ }^{176} \mathrm{Hf} /{ }^{177} \mathrm{Hf}$ data for Ryukyu and Central Honshu, and so is not shown. A weak negative correlation is present between ${ }^{143} \mathrm{Nd} /{ }^{144} \mathrm{Nd}$ and the $\mathrm{La} / \mathrm{Sm}$ ratio, while a positive, though possibly nonlinear, relationship exists between ${ }^{143} \mathrm{Nd} /{ }^{144} \mathrm{Nd}$ and the $\mathrm{Ba} / \mathrm{Nb}$ ratio (Figures $3 \mathrm{~b}$ and $3 \mathrm{c}$ ). A similar relationship exists between ${ }^{143} \mathrm{Nd} /{ }^{144} \mathrm{Nd}$ and $\mathrm{Zr} / \mathrm{Nb}$, though the correlation is somewhat weaker $\left(r^{2}=0.41\right.$, not shown). ${ }^{143} \mathrm{Nd} /{ }^{144} \mathrm{Nd}$ also correlates well with $\mathrm{Th} / \mathrm{U}$ (Figure $3 d)$. As shown in Figures $3 b$ and $3 d$, the arc average 

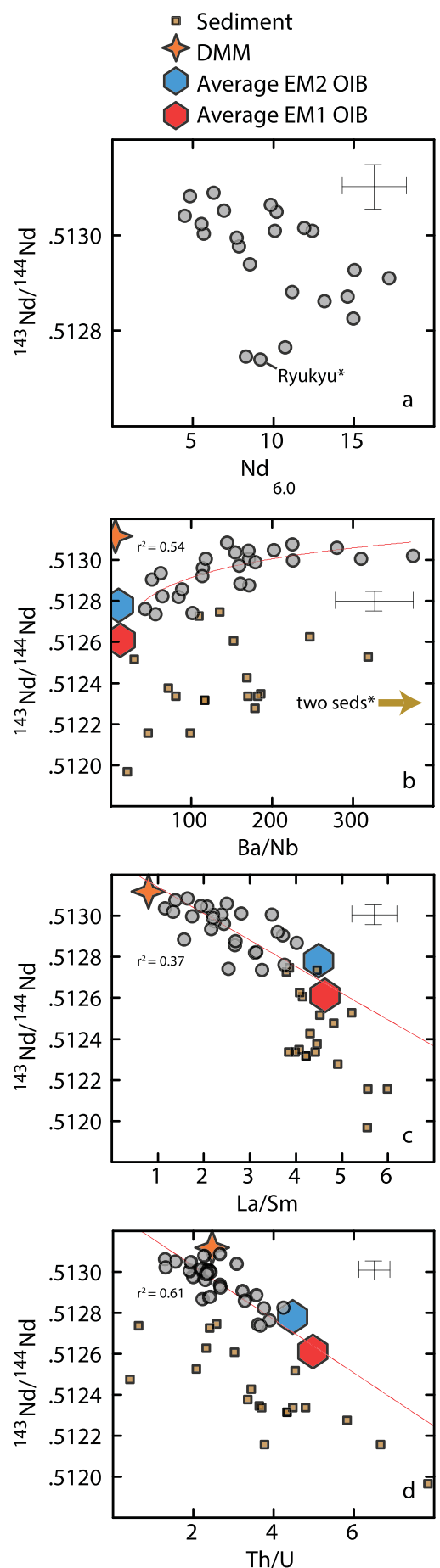

Figure 3. Correlations of ${ }^{143} \mathrm{Nd} /{ }^{144} \mathrm{Nd}$ with trace element parameters for global arc averages. (a) weak negative correlation between ${ }^{143} \mathrm{Nd} /{ }^{144} \mathrm{Nd}$ and $\mathrm{Nd}_{6.0}$. The three discrepant arcs with the lowest ${ }^{143} \mathrm{Nd} /{ }^{144} \mathrm{Nd}$ are Ryukyu, Central Honshu, and the Aegean. Due to insufficient data for a 6-value calculation at Ryukyu, the Ryukyu Mg\#55 value is plotted here instead. TL2015a demonstrated a 1:1 correlation between 6-values and Mg\#55 values, so the value shown is likely an accurate proxy of $\mathrm{Nd}_{6.0}$. (b) Positive correlation with $\mathrm{Ba} / \mathrm{Nb}$. ${ }^{*}$ The brown arrow points toward sediments from two segments (Central America and Colombia/Ecuador) with $\mathrm{Ba} / \mathrm{Nb}$ higher than the range shown in the figure, which are omitted to preserve the scale. (c and d) Negative correlations with La/Sm and Th/U. In panels 3b-3d, a comparison is made to depleted MORB (large orange star, data from Workman and Hart [2005]), the average compositions of EM type OIB sources (EM1: large blue hexagon, EM2: large red hexagon; data from Willbold and Stracke [2006], and the database of Stracke [2012]), and globally subducting sediments (small brown squares, data from Plank [2013] and Patino et al. [2000]). Note that global arcs span the range between MORB and OIB sources, and are significantly offset from sediment compositions.
${ }^{143} \mathrm{Nd} /{ }^{144} \mathrm{Nd}$ values range from estimates of the depleted MORB mantle (DMM) [Workman and Hart, 2005], to the average ${ }^{143} \mathrm{Nd} /{ }^{144} \mathrm{Nd}$ of EM type Ocean Island Basalts (OIBs, calculated from the database of Stracke [2012]). The arc front averages with the highest ${ }^{143} \mathrm{Nd} /{ }^{144} \mathrm{Nd}$ have far higher $\mathrm{Ba} / \mathrm{Nb}$ than oceanic basalts, similar to the $\mathrm{Ba} / \mathrm{Nb}$ values found in ocean sediments (from Plank [2013]), while arcs with ${ }^{143} \mathrm{Nd} /{ }^{144} \mathrm{Nd}$ values close to those found in EM-OIBs have lower $\mathrm{Ba} / \mathrm{Nb}$ (EM-OIB trace element averages calculated from the database of Willbold and Stracke [2006]). The global arc data span the range between DMM and EM-OIBs (Figures 3c and $3 \mathrm{~d}$ ). Arcs have lower $\mathrm{La} / \mathrm{Sm}$ than sediment, and a lower average Th/U ratio. No other strong correlations have been identified between isotope ratios and major element concentrations, trace element concentrations, or trace element ratios.

The average ${ }^{87} \mathrm{Sr} /{ }^{86} \mathrm{Sr}$ and ${ }^{143} \mathrm{Nd} /{ }^{144} \mathrm{Nd}$ values from the rear-arc database can be compared to the isotopic composition of arc front lavas. As discussed in section 2.1, the rear-arc database has been filtered to retain only samples with $\mathrm{Th} / \mathrm{Nb}$ ratios $<0.14$, which should preclude significant contribution of slab material to their source region. $\mathrm{Nd}$ and $\mathrm{Sr}$, like $\mathrm{Th}$, are relatively immobile in low temperature aqueous fluids [Spandler et al., 2007], and thus are only transferred from the slab to the wedge in significant quantities by slab melts. Rear-arc samples with low $\mathrm{Th} / \mathrm{Nb}$ ratios are therefore likely to have $\mathrm{Sr}$ and $\mathrm{Nd}$ isotopic values that represent the ambient mantle wedge. Among rear-arc averages, there is a near perfect linear correlation $\left(r^{2}=0.91\right)$ between ${ }^{87} \mathrm{Sr} /{ }^{86} \mathrm{Sr}$ and ${ }^{143} \mathrm{Nd} /{ }^{144} \mathrm{Nd}$ (Figure 4a), and this correlation is consistent with enrichment trends found in oceanic basalts, providing further evidence that these data are free from any modification by the slab. In detail, the rear-arc basalts appear to be bracketed by DMM and the EM1 subset of EMOIBs, as the EM2 average has higher ${ }^{143} \mathrm{Nd} /{ }^{144} \mathrm{Nd}$ at a given ${ }^{87} \mathrm{Sr} /{ }^{86} \mathrm{Sr}$. Figure $4 \mathrm{~b}$ shows that there is also a strong correlation $\left(r^{2}=0.80\right) \quad$ between average rear-arc ${ }^{143} \mathrm{Nd} /{ }^{144} \mathrm{Nd}$ values (filtered for low $\mathrm{Th} / \mathrm{Nb}$ ) and average arc front ${ }^{143} \mathrm{Nd} /{ }^{144} \mathrm{Nd}$. For ${ }^{143} \mathrm{Nd} /{ }^{144} \mathrm{Nd}$, some of the more depleted (high ${ }^{143} \mathrm{Nd} /{ }^{144} \mathrm{Nd}$ ) values deviate slightly from the 1:1 line (dotted black line). Where deviations from the 1:1 line occur, the higher ${ }^{143} \mathrm{Nd} /{ }^{144} \mathrm{Nd}$ is found in the rear-arc. The correlation between rear-arc and 
arc front values is poor for $\mathrm{Sr}$ isotopes (Figure 4c). All of the arc front ${ }^{87} \mathrm{Sr} /{ }^{86} \mathrm{Sr}$ values are higher than their rear-arc counterparts, and as with the Nd isotopes, rear-arcs with the most depleted (low ${ }^{87} \mathrm{Sr} /{ }^{86} \mathrm{Sr}$ ) values deviate farthest from the 1:1 line. There are no apparent correlations between arc front and rear-arc $\mathrm{Pb}$ isotope ratios (not shown).

\subsection{Correlations With Crustal Thickness (CT), Slab Thermal Parameter (Ф), Depth to Slab (H), and Slab Temperature}

TL2015a demonstrated correlations among major and trace element compositions of arc magmas, as well as correlations among chemical parameters and crustal thickness (CT; data sources listed in TL2015a). Strong correlations exist between crustal thickness and $\mathrm{Na}_{6.0}, \mathrm{Ca}_{6.0}, \mathrm{~K}_{6.0}$, and $\mathrm{P}_{6.0}$ (Figure 5, column 1). The correlations with elemental abundances are plotted here as 6-values, which are calculated using only samples with $5.5<$ wt $\% \mathrm{MgO}<6.5$. TL2015a demonstrated that these correlations are independent of the normalization scheme employed-bracketing by various Mg\# criteria or using raw average values produces nearly identical results to the data shown here.

To investigate additional processes that likely contribute to the chemical diversity of primary magmas, this analysis must be expanded to include additional subduction parameters (Figures 5-7). The thermal parameter, $\Phi$, is a combination of multiple subduction parameters, calculated as the product of the slab age (A), convergence rate $(\mathrm{V})$, and the sin of the slab dip angle $(\theta)$. It has been proposed as a proxy for the thermal state of the subducting slab [Kirby et al., 1991; England et al., 2004]. In all figures, $\Phi$ is calculated using the full spreading rate, which includes back-arc spreading where present, using the values from Syracuse and Abers [2006] or Syracuse et al. [2010]. If back-arc spreading rates are not included, all correlations with $\Phi$ are weakened. $\Phi$ correlates significantly with the major elements listed above (Figure 5, column 2; note log scale), though correlations with $\Phi$ are typically weaker than correlations with CT. Among the arc segments included in this study, there is a weak correlation between crustal thickness and $\Phi$ (Figure 8a), so it is unsurprising that many of the chemical indices that correlate with one of these parameters also correlate with the other. This correlation between crustal thickness and $\Phi$ appears to be mostly attributable to the slab age rather than $V \sin (\theta)$ (Figures $8 \mathrm{~b}$ and $8 \mathrm{c}$ ). The slab age term also produces more of the total variance in $\Phi$, with slab age varying by a factor of 23 , and $V \sin (\theta)$ varying by a factor of 16 . There are no correlations between major elements and the depth of the slab $(\mathrm{H})$ beneath the arc front (Figure 5, column 3). The sub-arc slab surface model temperatures reported by the D80 models of Syracuse et al. [2010] exhibit poor to absent correlations with major elements $\left(r^{2}<0.2\right.$, Figure 5 , column 4$)$.

As with the major elements, most incompatible trace elements correlate positively with crustal thickness and negatively with $\Phi$ (Figure 6). The positive correlations are particularly strong among the LREE, Sr, Zr, and $\mathrm{Ba}$, and are notably absent for the HREE. For most incompatible element abundances, the relative variation among arc segments spans a factor of 3 or 4, with the greatest enrichment at thick-crust, low $\Phi$ arcs. In contrast, total relative variation is limited to $50 \%$ for the HREE. The compatible trace elements V and Sc are anticorrelated with crustal thickness, with both of these elements decreasing by a factor of $\sim 2$ going from thin to thick-crust (Figure 6a). Many trace element ratios also correlate with crustal thickness and $\Phi$. For example, Dy/Yb, La/Sm, and $\mathrm{Zr} / \mathrm{Ti}$ all increase with crustal thickness and decrease with $\Phi$ (Figures 7a-7c). Isotopic ratios do not correlate with any subduction parameters, as shown for ${ }^{143} \mathrm{Nd} /{ }^{144} \mathrm{Nd}$ in Figure $7 \mathrm{~d}$. Trace element concentrations and trace element ratios do not correlate well with $\mathrm{H}$ or the model slab surface temperatures of Syracuse et al. [2010] (not shown), as was the case for the major elements (Figure 5).

\section{Discussion}

There are strong correlations among arc segment averaged element abundances and ratios, as well as correlations between these chemical parameters, crustal thickness, and the slab thermal parameter. An important question is what causes these correlations, and hence leads to the global diversity of primary arc magmas. This question can be considered in the context of two models, one based on wedge thermal structure, and the other based on slab thermal structure.

The wedge thermal structure (WTS) model attributes chemical diversity primarily to variable melting conditions in the mantle wedge caused by lithospheric thickness, and to a lesser extent by the convergence rate and slab dip. Variations in the wedge thermal structure lead to large differences in the pressure and temperature conditions of melting, and thus the extents of melting beneath arcs. In this model, the flux from the 


\section{QAGU Geochemistry, Geophysics, Geosystems}
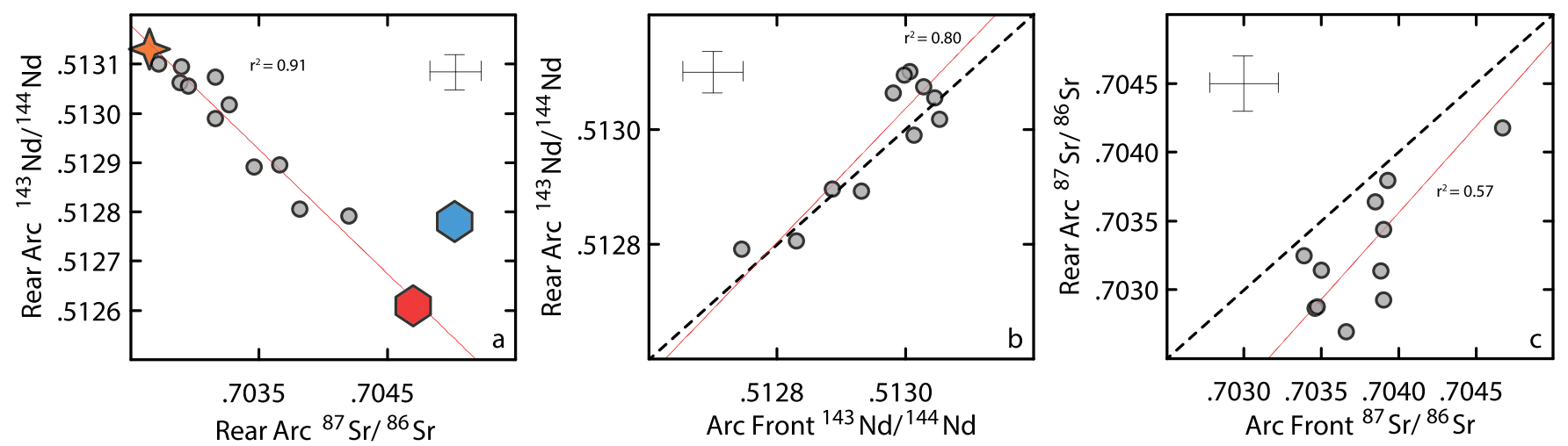

Figure 4. (a) Data from rear-arc volcanics filtered on the basis of Th/Nb ratio to ensure minimal subduction components (see text for details). The data range between depleted MORB and EM1-OIBs. (b and c) Rear-arc data are compared to global arc averages. Rear-arc ${ }^{143} \mathrm{Nd} /{ }^{144} \mathrm{Nd}$ values correlate well with the compositions of associated arc front volcanics, with a

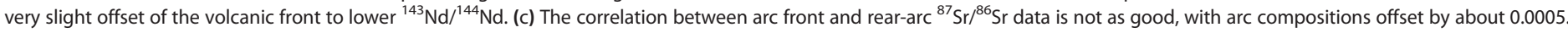
Symbols as in Figure 3. The rear-arc data compilation is available in the supporting information.

slab is assumed to be constant globally except for those elements strongly controlled by sediment composition [e.g., Plank and Langmuir, 1993].

The slab thermal structure (STS) model presumes that the thermal structure of the mantle wedge is relatively invariant. The slab thermal structure, however, varies because of differences in slab age, dip, and convergence rate. In the STS model, the temperature differences among slabs lead to a highly variable slab flux that changes the composition of the wedge prior to melting [e.g., Plank et al., 2009].

These two models represent the classic geochemical problem of separating source variations from variations in extents of melting. It is important to distinguish at the outset that there is abundant evidence for source variations in certain elements that have high concentrations in sediments and slab fluids (e.g., ${ }^{10} \mathrm{Be}$ : Morris and Tera [1989]; Ba and Th: Plank and Langmuir [1993]). Slab contributions produce variations in the ratios of highly incompatible elements with similar distribution coefficients (e.g., $\mathrm{Ba} / \mathrm{Th}, \mathrm{Th} / \mathrm{Nb}, \mathrm{Ce} / \mathrm{Pb}$ ) and imprint the distinct chemical signature of subduction zone lavas. The following treatment, however, emphasizes elements that are not overwhelmed by sediment (e.g., Nb, Zr, REE, P), but whose concentrations may nonetheless be strongly influenced by changing the temperature and volume of slab components. Many of these elements vary in concentration in arc volcanics by a factor of five-as much as the variations in Th and $\mathrm{Ba}$. Determining whether these variations are primarily a result of source changes due to slab flux (the STS model), or variable conditions of mantle wedge melting (the WTS model) can then provide constraints that enhance our understanding of the elements that are dominated by sediment.

The STS and WTS scenarios can be justified by different physical models and observations. The STS model assumption that the sub-arc mantle wedge thermal structure is similar for all arcs has been invoked to explain why arc fronts are localized even though slab dehydration likely takes place over a range of depths [Schmidt and Poli, 1998]. The mantle wedge thermal structure may also be moderated to some extent by limited variability of the depths at which slabs couple with the overlying asthenosphere [Wada and Wang, 2009]. The WTS model assumption that overlying plate thickness may regulate the wedge thermal structure has also been demonstrated, most recently by Karlstrom et al. [2014].

After discussing each of the end-member models, the possibility of a hybrid model is considered, along with the implications for overall fluxes from the slab to the wedge. It is useful first, however, to consider the pure end-member models: one with a constant slab flux and variable wedge thermal structure, and another with a variable slab flux and constant wedge thermal structure.

\subsection{The Wedge Thermal Structure (WTS) Model}

Plank and Langmuir [1988] proposed that correlations among major element compositions of arc magmas could be produced by variations in the extent of melting of the mantle wedge $(F)$. By assuming that $H$ was constant, as was generally accepted at that time, they inferred that the distance between the slab and the base of the crust, or the "length of the melting column," was the critical parameter in determining F. It is 


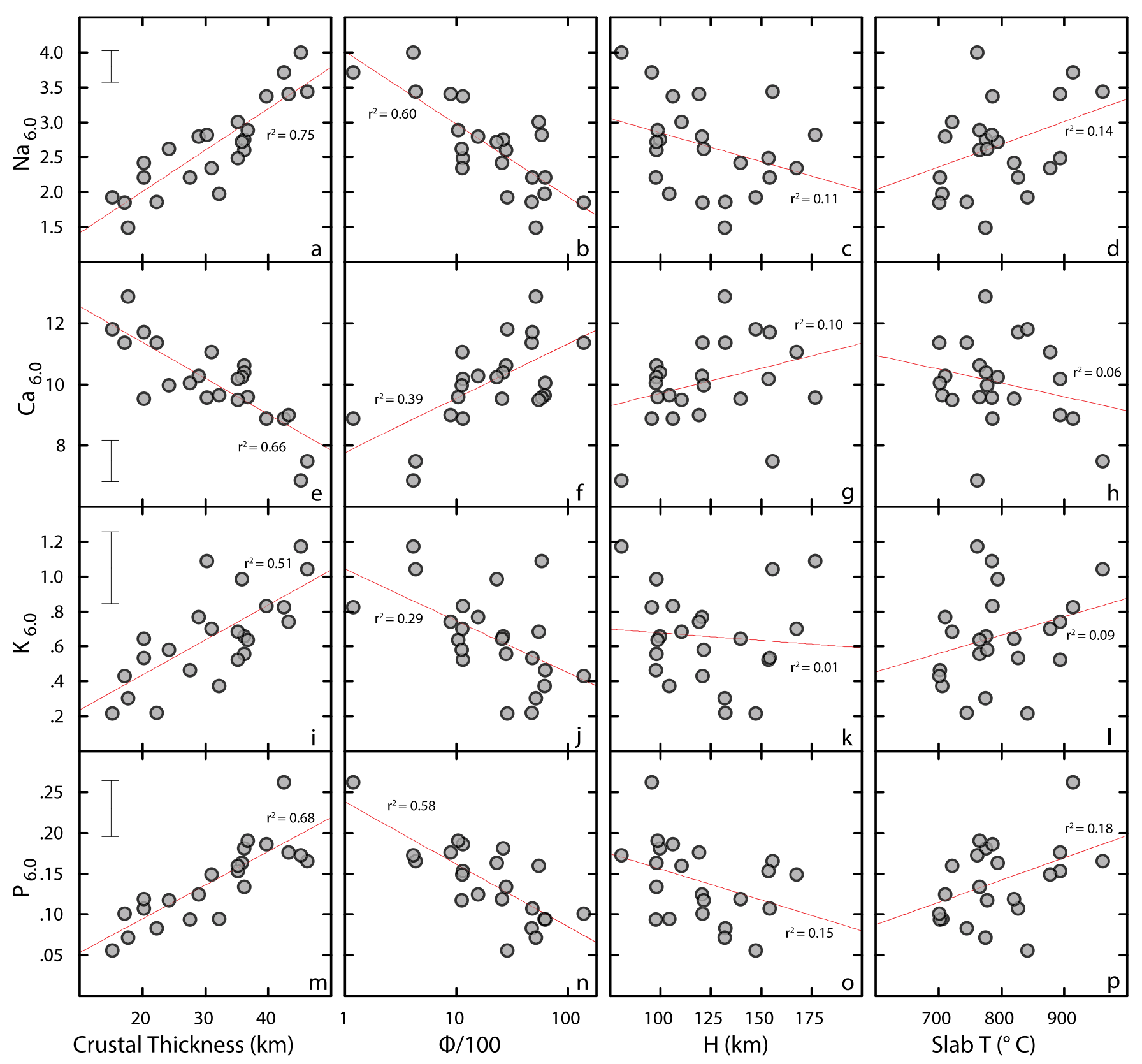

Figure 5. Relationships between major/minor element 6-values and subduction parameters. Column 1: In agreement with earlier results [Plank and Langmuir, 1988, TL2015], Ca, Na, K,

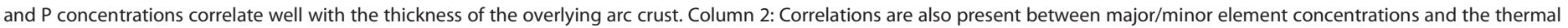

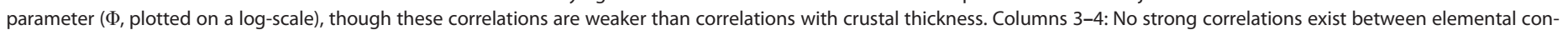

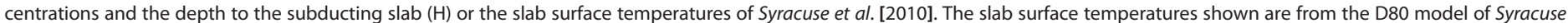
et al. [2010], though the lack of correlation is independent of the specific model choice.

evident from more recent data, however, that $\mathrm{H}$ varies considerably at convergent margins, and the "length of the melting column" cannot be the critical parameter (Figure 5, column 3).

The suggestion that varying $\mathrm{F}$ accounts for a large portion of the chemical variability of arc magmas, however, is still a viable hypothesis, though the physical mechanism controlling the extent of melting must differ from that proposed by Plank and Langmuir [1988]. In the model presented below, F is regulated by the thermal structure of the mantle wedge, which is influenced by the thickness of the overlying lithosphere. Lithospheric thickness likely correlates with the thickness of the overlying arc crust, because thicker crust pushes cold isotherms deeper. Lithospheric thickness may be an important control on the extent of melting 


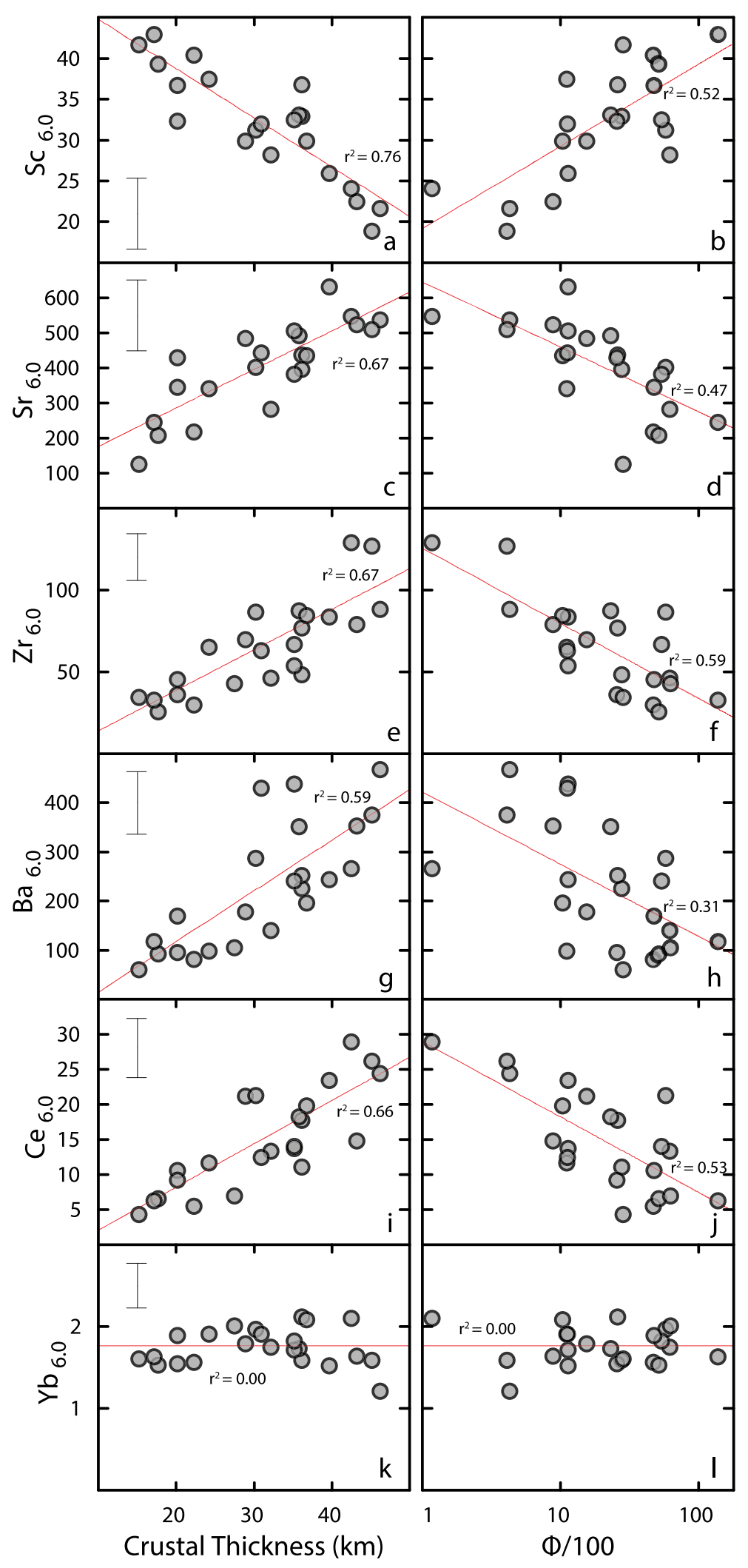

Figure 6. (a) Moderately compatible elements such as Sc correlate negatively with crustal thickness and positively with the thermal parameter $(\Phi$, plotted on a log-scale). Nearly all incompatible elements correlate positively with crustal thickness (left column) and negatively with $\Phi$ (right column). Note that correlations with $\Phi$ are all weaker than correlations with crustal thickness. Yb concentrations are relatively constant across all arc segments (two bottom plots, $\mathbf{k}$ and $\mathbf{I}$ ). 


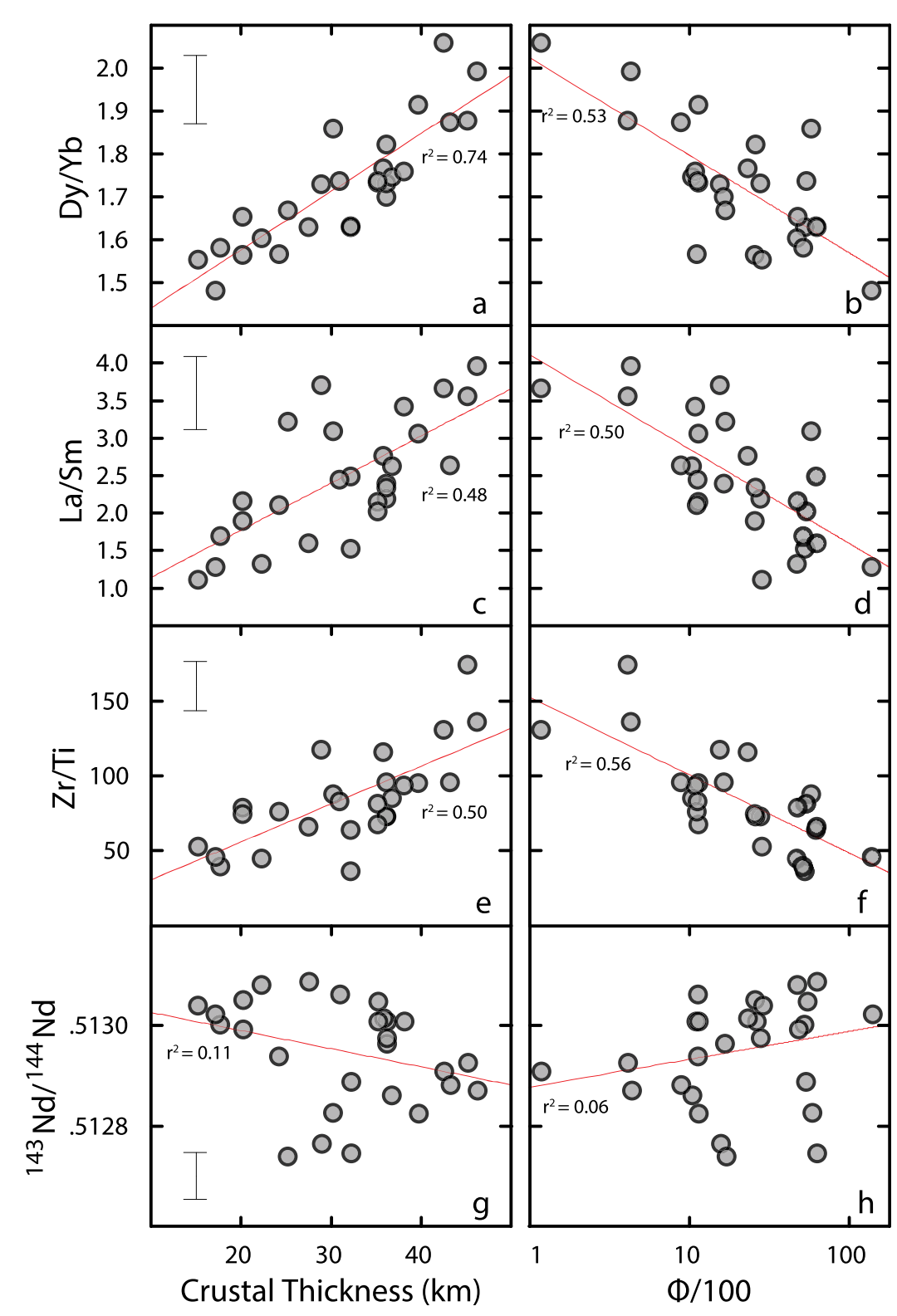

Figure 7. (a-f) The trace element ratios $\mathrm{Dy} / \mathrm{Yb}, \mathrm{La} / \mathrm{Sm}$, and $\mathrm{Zr} / \mathrm{Ti}$ all correlate positively with crustal thickness and negatively with the thermal parameter $(\Phi$, plotted on a log-scale). Crustal thickness correlates much more strongly with Dy/Yb than $\Phi$, but La/Sm and Zr/Ti have slightly stronger correlations with $\Phi$ than crustal thickness. ( $g$ and h) ${ }^{143} \mathrm{Nd} /{ }^{144} \mathrm{Nd}$ does not correlate with crustal thickness or $\Phi$, the same is true for other subduction parameters that are not shown here.

of the mantle wedge, because thicker lithosphere likely displaces melting to higher pressures and lower temperatures (see cartoon in Figure 9). A convenient measure of this effect on mantle melting is the parameter $T-T_{s}$, where $T_{s}$ is the anhydrous solidus temperature at a given pressure [e.g., Langmuir et al., 2006]. $T-T_{s}$ is a measure of the energy available for melting, so higher values lead to greater extents of melting (at a given $\mathrm{H}_{2} \mathrm{O}$ concentration). Increasing pressure increases $\mathrm{T}_{\mathrm{s}}$ and so melting at higher pressures decreases $\mathrm{T}$ $\mathrm{T}_{\mathrm{s}}$ and hence decreases the extent of melting. For a given $\mathrm{H}$, increasing lithospheric thickness may also displace the hottest wedge isotherms away from the trench, thus reducing the maximum temperature of the mantle beneath the arc front, which further reduces $\mathrm{T}_{-} \mathrm{T}_{\mathrm{s}}$ [Karlstrom et al., 2014]. By the same logic, varying $\mathrm{H}$ alone may not significantly affect $\mathrm{T}-\mathrm{T}_{\mathrm{S}}$, because an independent increase in $\mathrm{H}$ is likely to increase $\mathrm{P}$ and $\mathrm{T}$ simultaneously (Figures 9b and 9c).

The potential viability of this model (the WTS model) depends upon its ability to satisfy the new results presented here, such as the enrichment of a host of incompatible trace elements, the covariation of this 


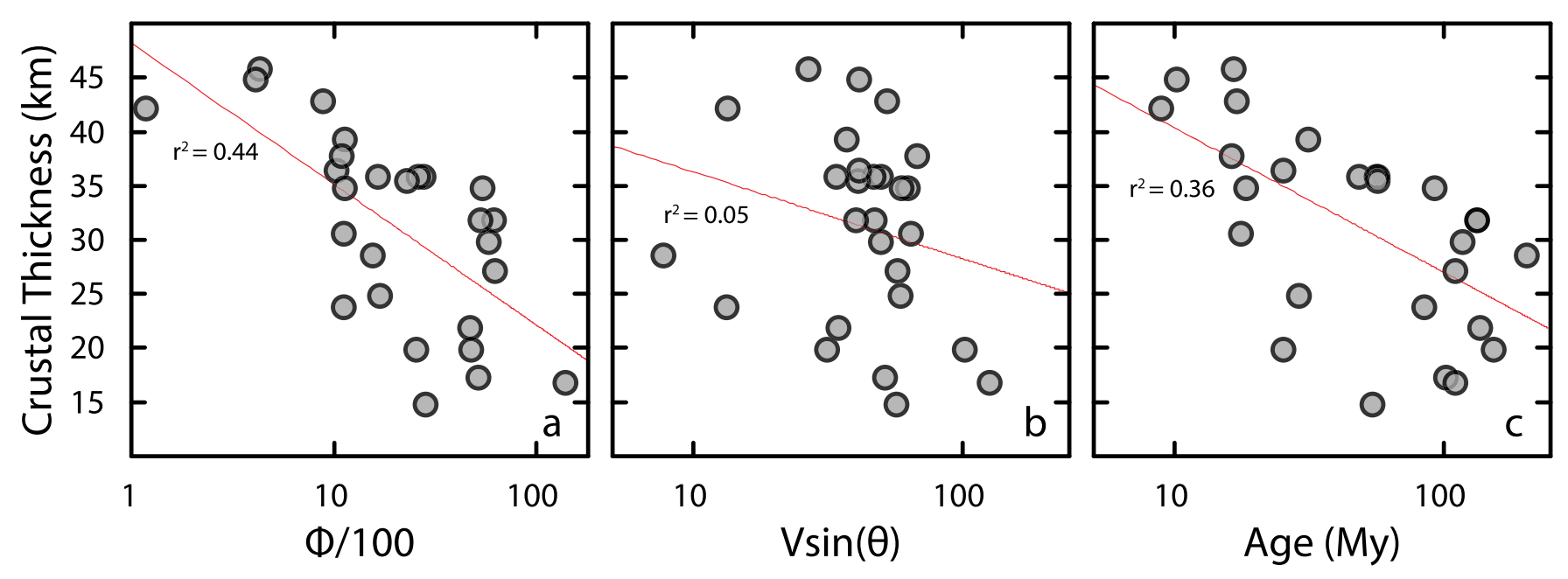

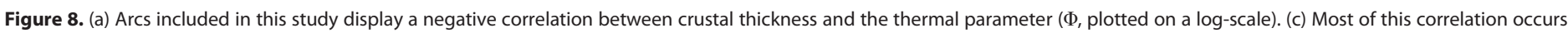
because crustal thickness correlates with slab age. (b) The other terms in the thermal parameter (Vsin $(\theta)$, where $\mathrm{V}$ is convergence rate and $\theta$ the slab dip) do not correlate with crustal thickness.

enrichment pattern with certain trace element ratios ( $\mathrm{Dy} / \mathrm{Yb}, \mathrm{La} / \mathrm{Sm}, \mathrm{Zr} / \mathrm{Sm}, \mathrm{Zr} / \mathrm{Ti}$ ), and the concurrent depletion of Sc and V. A particularly important new observation in this regard is the correlation between crustal thickness and $\mathrm{Dy} / \mathrm{Yb}$, as fractionation among the HREE does not occur during melting in the spinel peridotite stability field. This relationship requires that there be a significant signal from residual garnet transferred either from the deep mantle wedge or the slab.

The success of the WTS model is demonstrated in Figure 10. The global geochemical trends can be reproduced by assuming simple linear relationships between crustal thickness and the pressure and temperature of mantle melting. In order to reproduce the smooth correlation between crustal thickness and $\mathrm{Dy} / \mathrm{Yb}$, melting must occur within the garnet stability field, at pressures greater than $2 \mathrm{GPa}$. As arc crustal thickness increases from 15 to $50 \mathrm{~km}$, the model's pressure of melting increases linearly from 2 to 3.5 GPa and its temperature of melting decreases linearly from 1450 to $1300^{\circ} \mathrm{C}$. These pressure and temperature ranges are within $\mathrm{P}$ and $\mathrm{T}$ conditions of melting predicted by the dynamic models of Wilson et al. [2014]. Melt compositions are calculated using a single P and T for each arc. The mantle wedge source for each arc is calculated from a mantle composition [Workman and Hart, 2005] that has been modified by a slab addition consisting of 7\% addition of an N-MORB [Gale et al., 2013] melt, and 1\% addition of sediment melt. The 7\% addition of N-MORB melt is necessary to reproduce elemental abundances, and indicates that a significant flux of melted oceanic crust must be present at all arcs in the WTS model scenario. A single mean sediment composition was used, so that the mantle composition is constant for every arc. Details of the calculation of the mean sediment composition are given in the supporting information. Water content of the wedge source is fixed at $0.6 \mathrm{wt} \%$. Quantitative extents of melting were calculated using the equations of Katz et al. [2003], using an enthalpy of fusion of $180 \mathrm{cal} / \mathrm{g}$. The resulting range in the extent of melting is from $F \sim 0.05$ to $F \sim 0.20$. The parameterizations of subsolidus mantle modes, slab melt compositions, melting reaction coefficients, and element partition coefficients are available in the supporting information.

The goal of this model is not to emulate the full range of mantle processes that ultimately affect the compositions of primary magmas, but rather to determine if a simple model of varying wedge thermal structure can reproduce the coherent first-order variability among global arcs. The reality of wedge melting is of course far more complex than these simple models: the relationship between crustal thickness and the $P$ and $\mathrm{T}$ conditions of melting is likely not linear; $\mathrm{H}_{2} \mathrm{O}$ contents are likely not constant; melting probably occurs over a range of $\mathrm{P}$ and $\mathrm{T}$; and constant proportions of slab components are not added at every arc. As an example of the model problems, the linear parameterization of $\mathrm{P}$ and $\mathrm{T}$ with $\mathrm{CT}$ results in melting regions that are close to or within the slab at a few arcs that have very thick-crust and very shallow slab depths (such as Mexico). In reality, the very short melting columns in such arcs probably result in particularly low 


\section{QAGU Geochemistry, Geophysics, Geosystems}
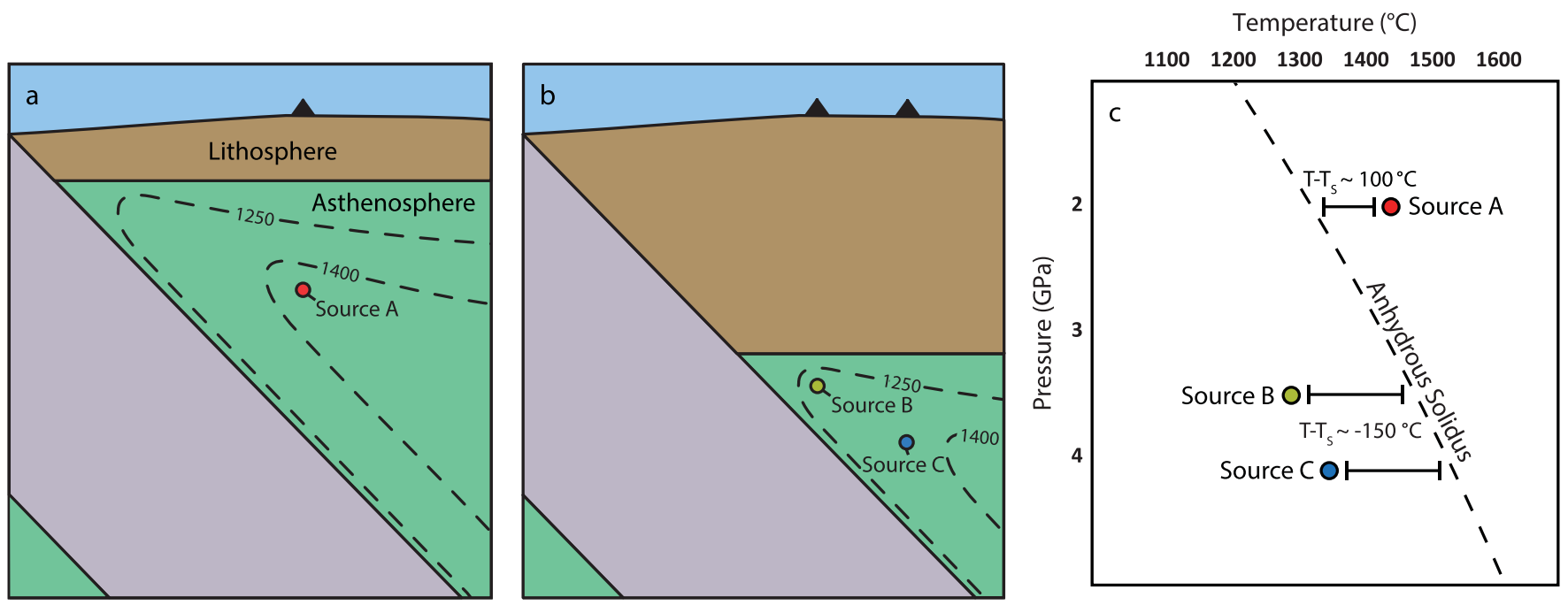

Figure 9. A cartoon illustrating the potential relationship between lithospheric thickness and the extent of melting, as proposed for the WTS model. As lithospheric thickness increases,

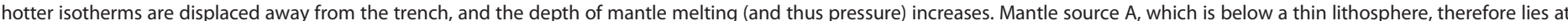

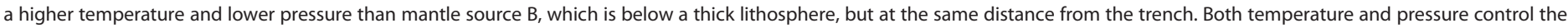
extent of melting, which is a function of the difference between the temperature of the mantle and the dry mantle solidus $\left(\mathrm{T}-\mathrm{T}_{\mathrm{s}}\right)$. $\mathrm{T}-\mathrm{T}_{\mathrm{s}}$ is about $250^{\circ} \mathrm{C}$ larger for source $\mathrm{A}$ than source $\mathrm{B}$. Variation in $\mathrm{H}$ can be accomplished either by shifting the arc front away from the trench (compare source $\mathrm{B}$ to source $\mathrm{C}$ ) or by changing the slab angle. Either of these changes may increase the source temperature, but will also increase the source pressure. As a result, there is no net change in $\mathrm{T}^{-} \mathrm{T}_{\mathrm{s}}$ and thus changing $\mathrm{H}$ alone may not affect the extent of melting.

sub-arc mantle temperatures, so the low extents of melting predicted by the model in these settings are expected [see Karlstrom et al., 2014, for physics-based description of this process]. Furthermore, the relationship between lithospheric thickness and crustal thickness among volcanic arcs is not actually known, and is a prediction of the potentially successful model, rather than a constrained model input. If the model is fundamentally correct, these complexities should ultimately be able to account for the some of scatter observed in Figures 1-7.

Figure 10 compares model outputs (green diamonds) with actual arc averages (gray circles). The enrichments of incompatible elements produced by the model closely reproduce the concurrent incompatible element enrichment (Figures 10a-10c) and Sc depletion (Figure 10d) observed in the global data set. The trends for $\mathrm{Zr} / \mathrm{Sm}$ and $\mathrm{Dy} / \mathrm{Yb}$ are also well reproduced (Figures $10 \mathrm{f}$ and $10 \mathrm{~g}$ ). These model results demonstrate the plausibility that variations in the extent of melting of the mantle wedge are a primary driver of global correlations between magma chemistry and crustal thickness. A model of varying extents of melting as a response to wedge thermal structure is thus a quantitatively viable explanation that accounts for the global chemical compositions of convergent margin volcanics.

Variations in major element concentrations are also important, though not explicitly modeled here. The most obvious major element trends are with $\mathrm{Na}, \mathrm{Ca}$, and $\mathrm{K}$, which are well known to vary with extent of melting [Jaques and Green, 1980; Klein and Langmuir, 1987]. Thick-crust arcs are also associated with high $\mathrm{Si}_{6.0}$ and low $\mathrm{Fe}_{6.0}$, and these relationships are likely to be somewhat more complicated [Plank and Langmuir, 1988; TL2015a]. It is difficult to assess these variations partly due to the lack of experimental data under hydrous conditions at high pressure and low extents of melting. Though the experiments of Baker et al. [1995], demonstrate that low $\mathrm{Fe}_{6.0}$ high $\mathrm{Si}_{6.0}$ liquids (much like those frequently found at thick-crust arcs) can be produced by low $\mathrm{F}$ melting, these experiments were anhydrous and at pressures of only $1 \mathrm{GPa}$. Balta et al. [2011] conducted hydrous, high P (3 GPa) experiments, and demonstrated that adding water can produce slightly elevated $\mathrm{SiO}_{2}$ concentrations, though these experiments do not attempt to evaluate the added effect of very low extents of melting. Lee et al. [2009] compiled experimental data to produce a thermobarometer for peridotite melts based on the activity of silica, and suggested that many Cascades lavas appear to have equilibrated at temperatures close to the Moho. Equilibration with the mantle just below the Moho is not necessarily inconsistent with the WTS model, as a garnet influence on trace elements could be inherited from melting at depth, followed by shallower reequilibration of some major elements. 


\section{Wedge Thermal Structure Model}

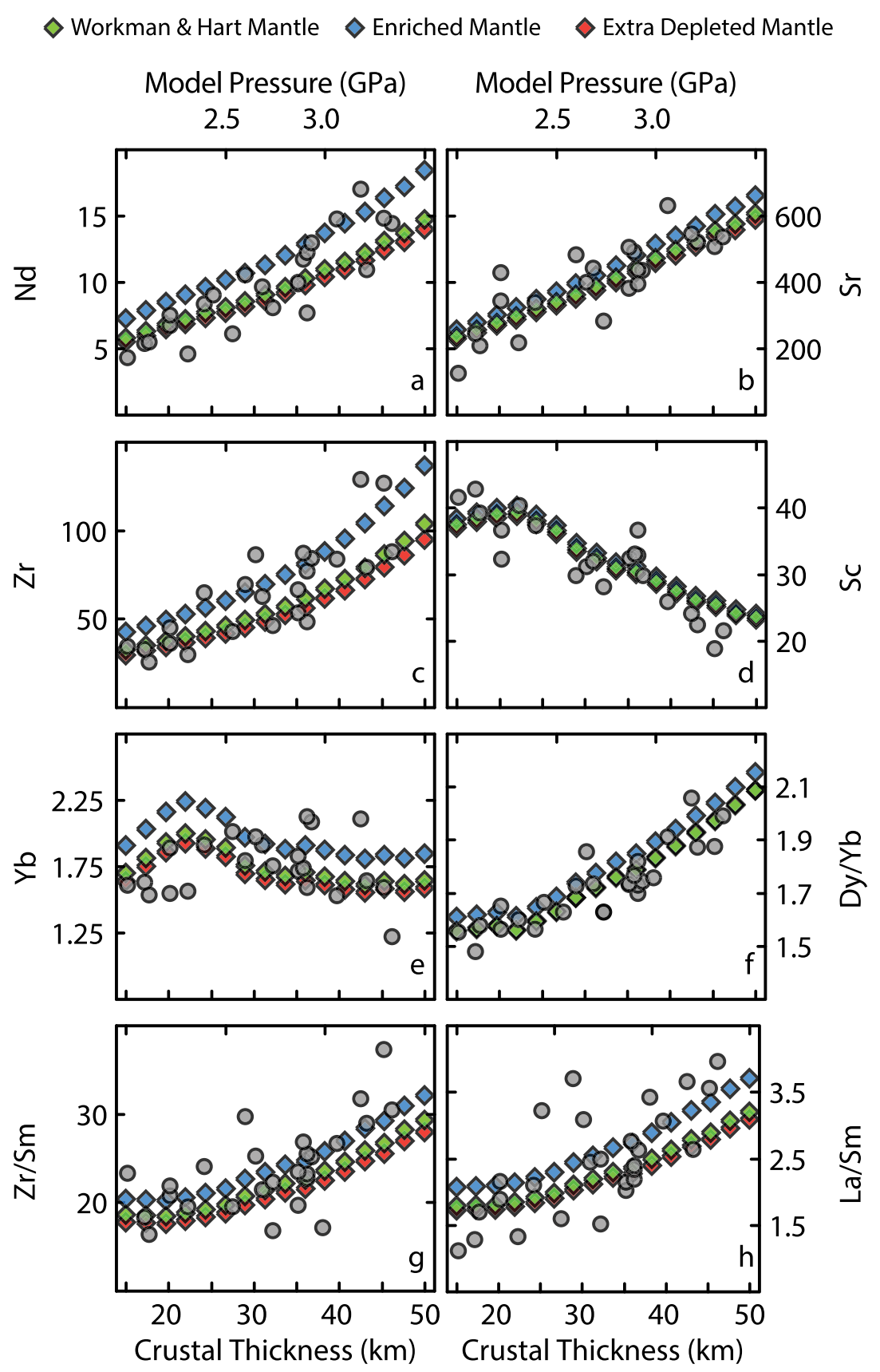

Figure 10. A comparison of the WTS model with average arc data. (bottom) Arc data are plotted against crustal thickness ( $x$ axis), and (top) model data are plotted against the model's pressure of melting, which scales linearly with crustal thickness ( $x$ axis). Green diamonds represent values calculated using the mantle composition of Workman and Hart [2005] as a starting composition. Blue diamonds use the Workman and Hart mantle with the addition of 2\% E-MORB from Gale et al. [2013], and red diamonds use the Workman and Hart mantle after extraction of $0.5 \%$ melt. The WTS model is successful at reproducing the trends in trace element compositions and ratios. For model details see text and supporting information.

\subsubsection{How Important is Heterogeneity of the Ambient Mantle Wedge?}

Some ratios, such as La/Sm (Figure 10h), vary to a greater extent than would be predicted by the melting model alone. The La/Sm ratio is sensitive not only to extent of melting, but also to the composition and quantity of sediment that is transferred to the mantle wedge in a given arc, and to the background 


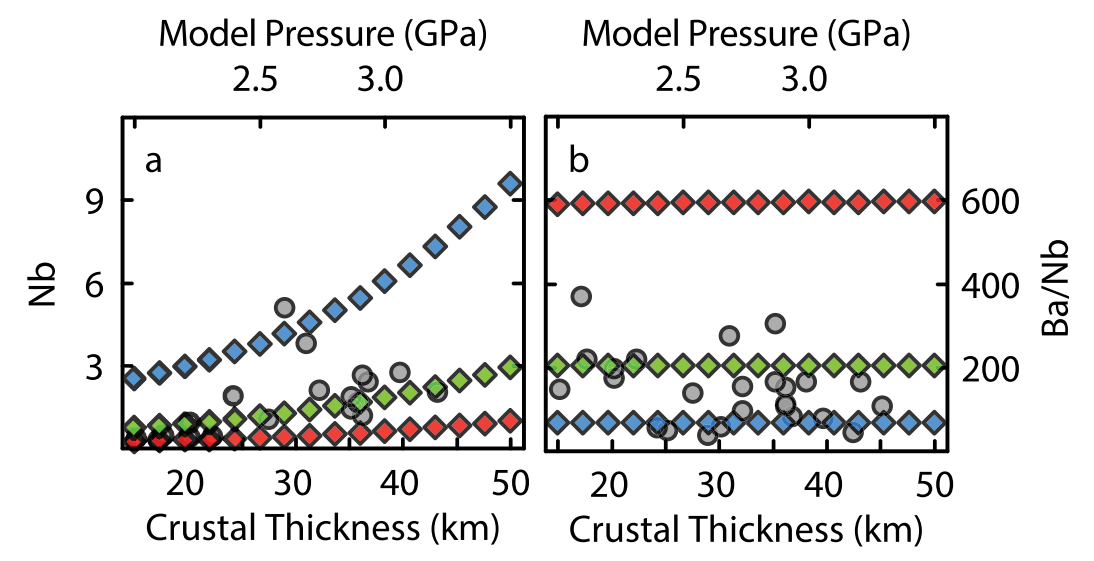

Figure 11. (a) Results of the WTS model for Nb concentrations and (b) the Ba/Nb ratio compared to actual arc data. Symbols as in Figure 10. Though there is not sufficient data to calculate $\mathrm{Nb}_{6.0}$ values for a number of arcs, this plot can be used to demonstrate the maximum allowable levels of source enrichment. In the WTS model, a maximum of $2 \%$ source enrichment can take place before exceeding observed $\mathrm{Nb}$ concentrations. Note the great sensitivity of the $\mathrm{Ba} / \mathrm{Nb}$ ratio to source enrichment and depletion.

enrichment of the ambient mantle wedge (the wedge prior to slab addition). Many arcs with low La/Sm are associated with back-arc basins, while particularly elevated La/Sm compositions, suggestive of an enriched ambient mantle wedge, appear to be present at several mature arcs with thick-crust. There is also evidence of enrichment of the mantle wedge in some locations based on rear-arc ${ }^{143} \mathrm{Nd} /{ }^{144} \mathrm{Nd}$ and ${ }^{87} \mathrm{Sr} /{ }^{86} \mathrm{Sr}$ systematics (Figure 4a), which indicates that mantle wedge enrichment may follow similar trends to the enrichment seen in EM1 type OIBs. A significant role for background mantle wedge compositions is also supported by the correlation between rear-arc and volcanic front $\mathrm{Nd}$ isotope ratios (Figure $4 \mathrm{~b}$ ). The proposal that enriched ambient mantle wedge compositions are associated with mature arcs, and can have large effects on magma compositions [see also Morris and Hart, 1983; Chin et al., 2014] therefore merits further consideration.

While variability in ambient mantle wedge enrichment can significantly affect certain trace element ratios and concentrations, it is unable to account for most of the chemical variability of the global dataset. The red and blue diamonds in Figure 10 demonstrate the effect of starting with an extra depleted or extra enriched mantle composition. Extra-depleted mantle is calculated by removing $0.5 \%$ melt from the mantle composition of Workman and Hart [2005]. Enriched mantle is calculated by adding 2\% E-MORB [Gale et al., 2013] to the ambient mantle, based on the assumption that enrichment processes controlling trace element abundances in the ambient mantle wedge follow the same trends observed in oceanic basalts, to first-order. It is apparent in Figure 10 that varying the enrichment of the ambient mantle accommodates some of the scatter on plots of compositional parameters versus crustal thickness, but that this effect is in most cases small compared to the chemical variability produced by changing the wedge thermal structure.

In these model calculations, $\mathrm{Nb}$ is treated as completely immobile from the slab to the mantle wedge, and so the maximum level of ambient mantle enrichment is constrained by the final $\mathrm{Nb}$ concentrations in the melt. As shown in Figure 11a, it is possible to account for the entire range of arc $\mathrm{Nb}$ compositions by varying mantle wedge enrichment alone. $\mathrm{Nb}$ is particularly sensitive to typical oceanic mantle enrichment and depletion processes, so $\mathrm{Nb}$ is a poor indicator of $\mathrm{F}$, unless the ambient mantle composition is somehow independently constrained. The same conclusion applies to any element that is not efficiently transferred from the slab to mantle wedge, but is highly incompatible during mantle wedge melting. Also of note is the observation that the $\mathrm{Ba} / \mathrm{Nb}$ ratio, which is typically considered indicative of variable slab contributions, is strongly influenced by the ambient mantle enrichment (Figure 11b). Common oceanic mantle enrichment processes could cause the Nb concentration in the ambient mantle wedge to vary by a factor of $\sim 3$. Depletion of the ambient mantle by back-arc basins can further increase this variability. Highly variable ambient mantle $\mathrm{Nb}$ concentrations would result in highly variable $\mathrm{Ba} / \mathrm{Nb}$ in arc basalts, even with a fixed slab input, despite the fact that $\mathrm{Ba}$ is almost entirely contributed from the slab [e.g., Plank and Langmuir, 1993]. Ambient mantle wedge variability of certain elements can therefore lead to large variations in certain arc front trace element ratios, and may account for the correlation between ${ }^{143} \mathrm{Nd} /{ }^{144} \mathrm{Nd}$ and $\mathrm{Ba} / \mathrm{Nb}$ shown in Figure $3 \mathrm{~b}$. 

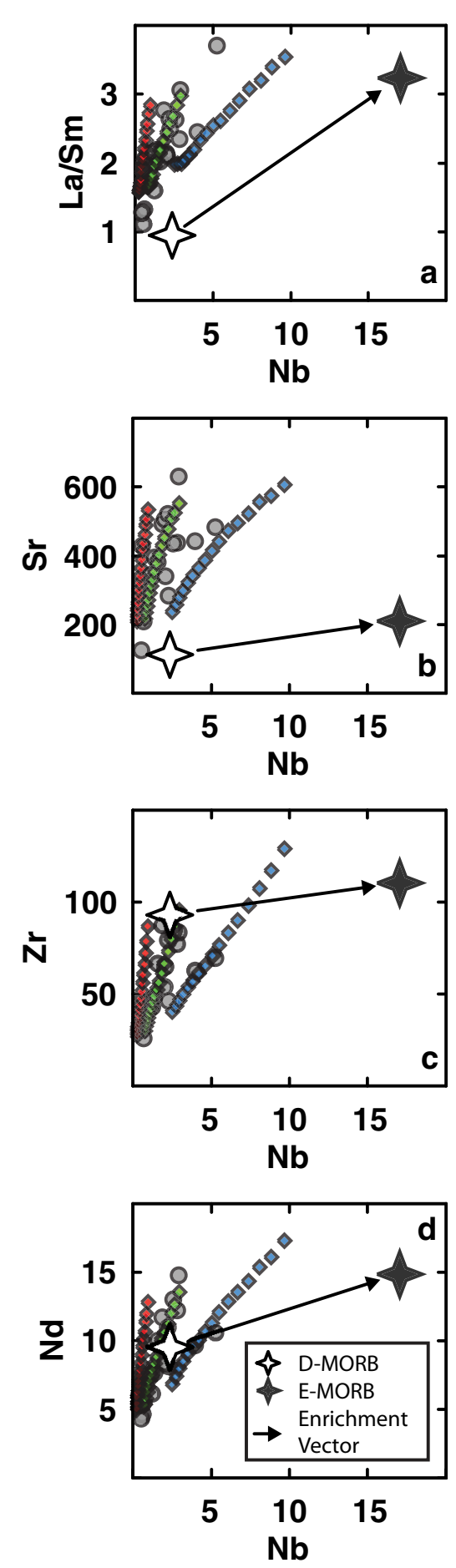

Figure 12. A comparison of the WTS model with average arc data. Symbols as in Figure 10. Nb concentrations are more sensitive to mantle enrichment processes than many other trace element concentrations and trace element ratios. The blue diamonds display model results using a starting mantle composition of Workman and Hart [2005] DMM composition plus 2\% E-MORB taken from Gale et al. [2013]. These enriched mantle melts intersect the highest arc Nb concentrations, and any additional mantle enrichment would generate compositions more enriched in $\mathrm{Nb}$ than are observed. It is also apparent from these plots that trends produced by typical mantle enrichment and depletion processes (black arrows connecting the D-MORB and EMORB values from Gale et al. [2013]) generate trends orthogonal to the observed data, while trends generated by variable extents of mantle melting are more or less parallel to the observed data.
Within the context of the WTS model, mantle enrichment by $2 \%$ addition of E-MORB is an upper limit. At this maximum level of enrichment, most bulk elemental compositions are barely altered, but $\mathrm{Nb}$ concentrations vary significantly. Figure 12 demonstrates both the effect of changing $F$ and the effect of source enrichment and depletion of the ambient mantle for $\mathrm{La} / \mathrm{Sm}$ ratio and $\mathrm{Sr}, \mathrm{Zr}$, and $\mathrm{Nd}$ concentrations as compared to $\mathrm{Nb}$. As in Figures 10 and 11, the red, green, and blue diamonds show the range of melt compositions produced by varying the extent of melting of a given starting mantle composition. The blue diamonds, which use the Workman and Hart mantle plus 2\% E-MORB, intersect those arcs with the highest average $\mathrm{Nb}$. Additional source enrichment would produce curves plotting well to the right of the observed values (gray circles).

The plots also illustrate that while ambient mantle wedge heterogeneity may be significant, it is not sufficient to explain the overall global trends. Mantle wedge heterogeneity does not reproduce the slope of trends seen for $\mathrm{La} / \mathrm{Sm}$ versus $\mathrm{Nb}$, and produces negligible variability in $\mathrm{Sr}, \mathrm{Zr}$, and $\mathrm{Nd}$ abundances as compared to the range observed for global arcs. It is also clear from Figure 12 that the range of average arc front compositions aligns well with the curves expected from varying the extent of mantle melting, but is essentially orthogonal to the compositional vectors associated with enrichment and depletion processes in oceanic basalts. That said, mantle heterogeneity could certainly contribute to the scatter in the arc compositions.

The importance of wedge heterogeneity varies for different element abundances, ratios and isotope ratios. Since ${ }^{143} \mathrm{Nd} /{ }^{144} \mathrm{Nd}$ shows strong dependence on wedge composition (see Figure 4b), correlations with $\mathrm{Nd}$ isotopes can potentially be used to test the importance of the wedge heterogeneity signal. The weak correlation between ${ }^{143} \mathrm{Nd} /{ }^{144} \mathrm{Nd}$ and La/Sm is evidence for a weak, but detectable effect of mantle heterogeneity on $\mathrm{La} / \mathrm{Sm}$. The somewhat stronger correlation between ${ }^{143} \mathrm{Nd} /{ }^{144} \mathrm{Nd}$ and $\mathrm{Th} / \mathrm{U}$ may indicate a more prominent role for mantle heterogeneity in altering this ratio.

These considerations show the importance of mantle wedge heterogeneity to the global variability of arc front volcanics. For some elements (e.g., Nb) it is very important. For Nd isotopes it may be nearly determinative. For some trace element ratios ( $\mathrm{La} / \mathrm{Sm}, \mathrm{Th} / \mathrm{U}, \mathrm{Ba} / \mathrm{Nb}$ ), it appears to contribute significantly. The overall global systematics, however, are not accounted for by heterogeneity (Figure 12). Modest heterogeneity in the ambient mantle wedge is thus an important complement to the successful WTS model.

\subsubsection{Further Tests of the Wedge Thermal Structure (WTS) Model}

The WTS model can be further tested by determining whether the fit to chemical indices is improved by including other subduction parameters relevant to the thermal conditions of the wedge. In addition to the effect of crustal thickness on $\mathrm{T}_{\mathrm{S}} \mathrm{T}_{\mathrm{s}}$ convergence rate and slab dip also influence the wedge 
thermal structure [e.g., England and Katz, 2010]. Faster plate convergence (V) increases the flux of hot mantle into the wedge corner, raising the wedge temperature beneath the arc. Increasing slab dip $(\theta)$ increases the separation between the thermal boundary layers of the subducting plate and overlying lithosphere, also influencing wedge temperature. Thermal models show that wedge temperature should scale with $V \sin (\theta)$ [e.g., England and Katz, 2010; Wada and Wang, 2009]. At a given distance from the trench, increased $\mathrm{V} \sin (\theta)$ should lead to larger $\mathrm{T}-\mathrm{T}_{\mathrm{s}}$ and greater extents of melting, and thus correlate with the chemical parameters.

To test this possibility, Figure $13 \mathrm{~b}$ plots $\mathrm{V} \sin (\theta)$ versus the residuals of a linear regression between $\mathrm{Na}_{6.0}$ and crustal thickness (see Figure 13a). The plate velocities used in Figure 13 have back-arc spreading rates removed, following the logic of England et al. [2004], who suggested that additional heat advection produced by back-arc spreading is likely to be directed toward the spreading center itself rather than the wedge corner. An increase in $\mathrm{V} \sin (\theta)$ should increase values of $\mathrm{T}-\mathrm{T}_{\mathrm{s}}$ and thus lower $\mathrm{Na}_{6.0}$. This will lead to a negative residual for $\mathrm{Na}_{6.0}$ versus crustal thickness, and hence a negative correlation between $\mathrm{V} \sin (\theta)$ and the residuals, as is observed in Figure 13b. For points that have residuals with an absolute value greater than $0.1,88 \%$ have positive residuals when $V \sin (\theta)<40$, while $82 \%$ have negative residuals when $V \sin (\theta)>40$. Including both $V \sin (\theta)$ and crustal thickness in a multiple regression significantly improves predictions of chemical parameters, with $r^{2}=0.83$ for $\mathrm{Na}_{6.0}$ (Figure 13c) and $p$ values for each independent variable well under 0.01 . While the function relating $\mathrm{CT}, \mathrm{V} \sin (\theta)$, and $\mathrm{Na}_{6.0}$ is unlikely to be linear in reality, the multiple regression approach still provides a useful first-order assessment. The fact that inclusion of $V \sin (\theta)$ with lithospheric thickness improves the fit of the data to a wedge melting model lends confidence to the wedge melting hypothesis.

The parameter $V \sin (\theta)$ also affects the slab thermal structure, so variations in slab thermal structure might also contribute to the improved results of the multiple regression. In addition to convergence velocity and dip, however, slab thermal structure is strongly influenced by slab age. If the slab thermal structure is the critical variable, then incorporating the full slab thermal parameter should produce better predictions of chemical parameters than $V \sin (\theta)$ alone. This is not the case. The fit is slightly degraded $\left(r^{2}\right.$ of 0.81 versus 0.83 ) if slab age is included. More importantly, the slab thermal parameter should in theory provide a better analog for the slab thermal state if convergence rates including back-arc spreading are used [Jarrard, 1986]. In this case, predictions of $\mathrm{Na}_{6.0}$ are not improved at all compared to the regression using $\mathrm{CT}$ alone. This analysis suggests that wedge rather than slab thermal structure is the important parameter.

\subsection{Evaluation of the Slab Thermal Structure (STS) Model}

Slab temperatures must vary among arcs. The importance of the slab thermal parameter, for example, is clearly indicated by its relationship with the maximum depths of earthquakes among subduction zones [Jarrard, 1986]. As shown above, the thermal parameter $(\Phi)$ also correlates with several major element concentrations, trace element concentrations, and trace element ratios, though correlations with $\Phi$ are typically weaker than those with crustal thickness. These correlations lend credence to the hypothesis that erupted magma compositions are controlled by the thermal state of the subducting slab [e.g., Plank et al., 2009; Cooper et al., 2012].

These factors motivate the second end-member model, the slab thermal structure model, in which the slab flux to the mantle wedge is variable, while the mantle thermal structure is constant. The essence of the STS model is that increasing slab temperature leads to higher concentrations of elements in the slab melt, and a higher mass flux of slab material into the mantle wedge. Like the WTS model, the STS model has many complexities that are difficult to take into account. Large thermal gradients occur in the slab at any depth, and both dehydration and melting are progressive open system processes. Slabs have variable compositions and form at different spreading rates with different sediment compositions [Plank and Langmuir, 1998]. There is evidence for multiple slab components in many arcs [e.g., Miller et al., 1994; Elliott et al., 1997]. The variable slab output interacts with and flows through the mantle wedge along pathways that are poorly constrained [e.g., Wilson et al., 2014], and so on.

Despite these complexities, a first-order evaluation is possible. The model takes a constant wedge thermal structure and adds slab components, varying slab melt compositions and total slab flux as a function of slab temperature, from 800 to $1000^{\circ} \mathrm{C}$. Model details and the MATLAB scripts used to generate all model results are available in the supporting information. The model has the following conditions: 


\section{QAGU Geochemistry, Geophysics, Geosystems}
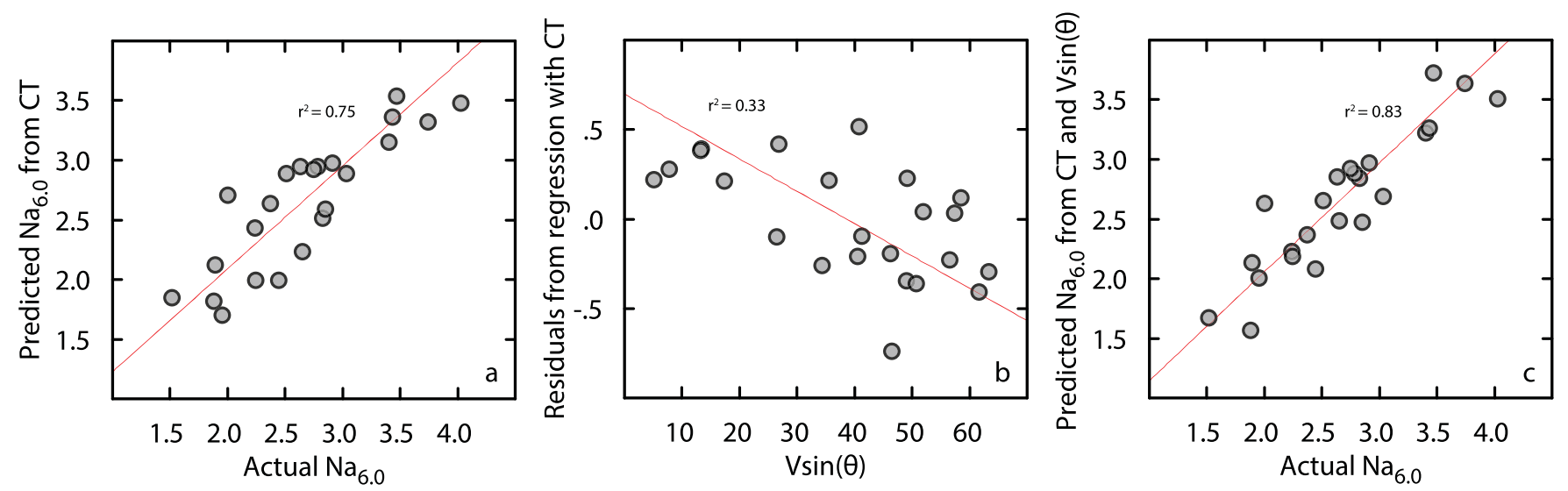

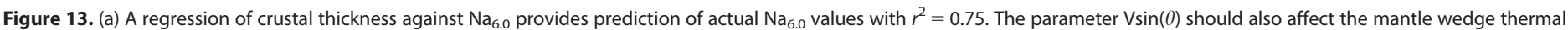
structure, hence if wedge thermal structure were the significant variable, residuals from crustal thickness versus $\mathrm{Na}_{6.0}$ should correlate $\mathrm{Vsin}(\theta)$. Figure $13 \mathrm{~b}$ shows that this is indeed the case. (c) A multiple linear regression of both $\mathrm{CT}$ and $\mathrm{V} \sin (\theta)$ improves predictions of $\mathrm{Na}_{6.0}$.

1. A constant wedge thermal structure is used, with melts forming at $1.8 \mathrm{GPa}$ and $1350^{\circ} \mathrm{C}$. These values were selected because they provide a successful model.

2. The ambient wedge composition is constant, with the composition of DMM from Workman and Hart [2005].

3. $\mathrm{H}_{2} \mathrm{O}$ contents in the mantle, and thus the extents of mantle melting, vary based on the amount of slab addition and the $\mathrm{H}_{2} \mathrm{O}$ contents of slab melts. The $\mathrm{H}_{2} \mathrm{O}$ contents of slab melts vary as a function of slab temperature.

4. Elements potentially dominated by a low temperature aqueous fluid flux (such as $\mathrm{Cs}$ and $\mathrm{Pb}$ ) are not considered.

5. The slab component varies in composition only as a function of slab temperature, constrained by experimental results of Hermann and Rubatto [2009] and Kessel et al. [2005].

6. The total mass flux of slab melts increases with increasing slab temperature.

Figure 14 demonstrates that a successful STS model can be produced such that average arc data fall between a cold slab with small amounts of slab addition, and a hot slab with high amounts of slab addition. The figure also demonstrates that a wide variety of models are possible, as long as there are large variations in slab temperature. The selection of parameters is sufficiently unconstrained that these results do not provide a real test of this model, but they do demonstrate that such models cannot be ruled out. It is also useful to consider the common features of all successful STS model implementations, and what these imply for convergent margin processes.

One common feature of successful STS models is that the extent of melting of the mantle wedge remains roughly constant, between $\mathrm{F}=0.15$ and $\mathrm{F}=0.20$. This result is necessary to simultaneously produce the variations in element ratios and abundances. To produce the low end of global $\mathrm{Dy} / \mathrm{Yb}$, garnet cannot be present in the mantle wedge. Within the framework of the STS model, there is no mechanism to regulate the garnet contents of the residual mantle wedge, and so all melting occurs outside the garnet stability field. Possible alternatives to this scenario are discussed in a later section. The AOC melting experiments of Kessel et al. [2005] and the sediment melting experiments of Hermann and Rubatto [2009] indicate that the bulk D for Dy between a hydrous melt and a subducting slab is at least 5, while the bulk $D$ for $\mathrm{Yb}$ is $>15-20$. As a consequence, although the Dy/Yb ratios of slab melts are high, the HREE concentrations in slab melts are very low. Because slab melts have very low $\mathrm{Yb}$, slab melt addition does not significantly affect mantle $\mathrm{Yb}$ concentration. In the absence of residual garnet, $\mathrm{Yb}$ is an incompatible element during mantle melting, so $\mathrm{Yb}$ concentrations in mantle melts vary as a function of $F$. As was shown in Figures $6 \mathrm{~m}$ and $6 \mathrm{n}, \mathrm{Yb}$ concentrations of averaged arc lavas are relatively constant. As a consequence, to reproduce the global Yb concentrations in the STS model, F can vary by no more than a factor of 1.3 , and the variation is not systematic among arcs.

High extents of melting are also necessary from consideration of the Dy/Yb ratio. If variations in the $\mathrm{Dy} / \mathrm{Yb}$ ratios are generated by variable slab flux rather than by variable conditions within the mantle wedge, then 
the $\mathrm{Dy} / \mathrm{Yb}$ ratio of the source must change as a consequence of slab addition. Because of the low HREE concentrations in the slab component, a large slab flux is required to reach the upper range of $\mathrm{Dy} / \mathrm{Yb}$ found globally. For arcs with high Dy/Yb such as the Cascades, Mexico, and Colombia/Ecuador, almost 30\% slab melt must be added to the mantle source. Such a high slab flux then leads to sources with very high concentrations of many elements (including Dy), requiring high extents of melting to match arc values.

The requirement for high $\mathrm{F}$ at all arcs appears to be a robust requirement of STS models. The STS model is able to produce this result because at cooler slab temperatures the slab mass flux is low, and the slab melt has high water content, while for hot slabs there is a larger mass flux with lower water content. Water contents in the wedge thus fall in a narrow range, and arc magmas all have roughly the same amount of water in their primary magmas. This model is therefore able to reproduce the results from melt inclusions where many arc volcanoes appear to have similar primary water contents [Plank et al., 2013]. These are major contrasts with successful WTS models, where extents of melting vary from $\sim 5 \%$ to $\sim 20 \%$ and water contents vary inversely with the extent of melting.

\subsubsection{Further Tests of Slab Thermal Structure Model}

The STS model adequately reproduces the global trends in arc magmas, but in its current form it does not adequately reproduce the observed range in Sc. In the WTS model, low Sc contents for thick-crust arcs result from garnet in the mantle wedge residue. In the STS model, the maximum variation in Sc is $30 \%$, equal to the amount of dilution produced by adding $30 \%$ of a slab melt that is virtually Sc free. A potential solution to this problem would be for large volumes of slab melt to react significantly with the mantle wedge, producing elevated modal pyroxene and a high bulk D for Sc. A similar mechanism has been proposed by Straub et al. [2013] to account for both high whole rock $\mathrm{SiO}_{2}$ contents and high olivine Ni contents in the Mexican arc, though that study found that the Dy/Yb ratio was unaffected by slab additions.

The observation that $\mathrm{H}$ varies substantially among arcs provides another test of the STS model's feasibility. Slabs at greater depth are hotter [Syracuse et al., 2010], so a relationship between $\mathrm{H}$ and magma chemistry is expected. This relationship is not observed (Figure 5, column 3). One can better quantify this test by using slab surface temperature, which takes into account all the subduction parameters. No correlations are found between arc chemical compositions and the calculated slab surface temperatures (Figure 5, column 4) of Syracuse et al. [2010]. The apparent contradiction of this result with the results from $\mathrm{H}_{2} \mathrm{O} / \mathrm{Ce}$ ratios [Cooper et al., 2012] is discussed further below.

The lack of correlations between predicted sub-arc slab surface temperatures and magma chemistry is perhaps less surprising than it may seem at first glance. Though slab surface temperatures must increase with depth, the value of $\mathrm{T}_{\mathrm{s}}$ on the slab surface may peak well before reaching the arc front. A simple parameterization of the slab solidus (taken from Cooper et al. [2012]) compared to the slab surface profiles [Syracuse et al., 2010] of two arcs with large values of $\mathrm{H}$ (Figure 15) illustrates this fact. Figure 15 demonstrates that, the maximum extent of slab melting for both Colombia/Ecuador and the Northern Marianas, which should occur when the difference between the slab temperature and the slab solidus is greatest, may be reached well before the arc front. If true, then the temperature of the slab directly beneath the arc front may not be a relevant parameter at these arcs. The possibility that temperatures directly beneath the arc are not the relevant parameter is also supported by the findings of Wilson et al. [2014], who developed dynamic models that incorporate the effects of compaction. In these models, fluids released from the slab at P and T conditions well past the arc front may flow upslope on the slab back into the nose of the mantle wedge.

Despite these caveats, slab temperature may be an important factor in controlling arc chemical compositions. The experimental data and physical processes are sufficiently unconstrained that definitive tests other than plausibility are not yet possible. The fact remains, however, that the wedge thermal structure model not only accounts well for the data to first-order, but also improves when additional subduction parameters are considered. The slab temperature models do not yet have this supporting evidence.

\section{Additional Constraints From Isotopes, Rear-Arc Lavas, and Sediments}

Eleven of the arc segments included in the dataset have additional constraints from both rear-arc volcanics and subducting sediment compositions. For these arcs, more rigorous testing of the models is possible, as well as determination of the proportions of $\mathrm{Sr}$ and $\mathrm{Nd}$ erupted at arcs that originate from sediment, AOC, or the ambient mantle. 

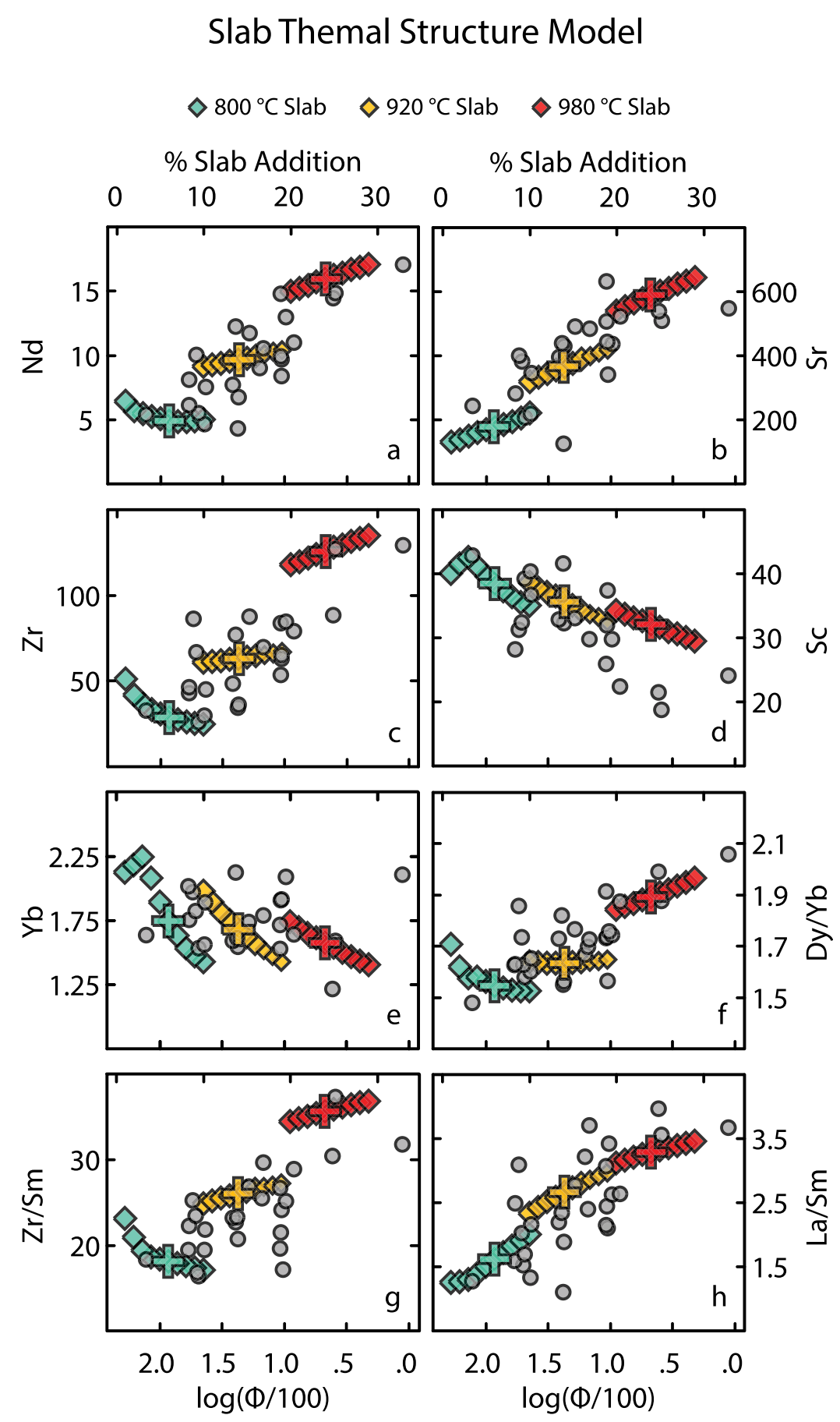

Figure 14. A comparison of the STS model with average arc data. The STS model invokes both increasing slab contributions and increasing slab temperatures that correspond to a decreasing slab thermal parameter $(\Phi)$. The arc data are plotted against log $(\Phi / 100)($ bottom $x$ axis), while (top $x$ axis) the model data are plotted against the model's $\%$ slab addition which scales linearly with log( $(\Phi / 100)$. The figure illustrates the combined effects of increasing slab proportions and increasing slab temperatures, which are the basis of the STS model. For the model output shown here, slab melts at $800^{\circ} \mathrm{C}$ are displayed for the range of slab additions between $1 \%$ and $10 \%$ (green diamonds), slab melts at $920^{\circ} \mathrm{C}$ are displayed for slab additions between $10 \%$ and $20 \%$ (yellow diamonds), and slab melts at $980^{\circ} \mathrm{C}$ are displayed for slab additions between $20 \%$ and $30 \%$ (red diamonds). Because these results show incremental slab temperature variations but continuous variation of the \% slab addition, there is some variation in the slab to mantle $\mathrm{H}_{2} \mathrm{O}$ flux, and thus the extent of mantle melting ( $\mathrm{F}$ varies between $\sim 0.15$ and $\sim 0.2$ ). If both of these factors varied continuously, $F$ would be constant. To demonstrate the path of constant $F$, the crosses displayed on each panel indicate the model outputs for which $F=0.19$. In this parameterization, up to $30 \%$ slab addition from a $980^{\circ} \mathrm{C}$ slab is required for the most enriched arc segments. With the exception of Sc (panel d), the STS model is able to reproduce the average arc data well. 


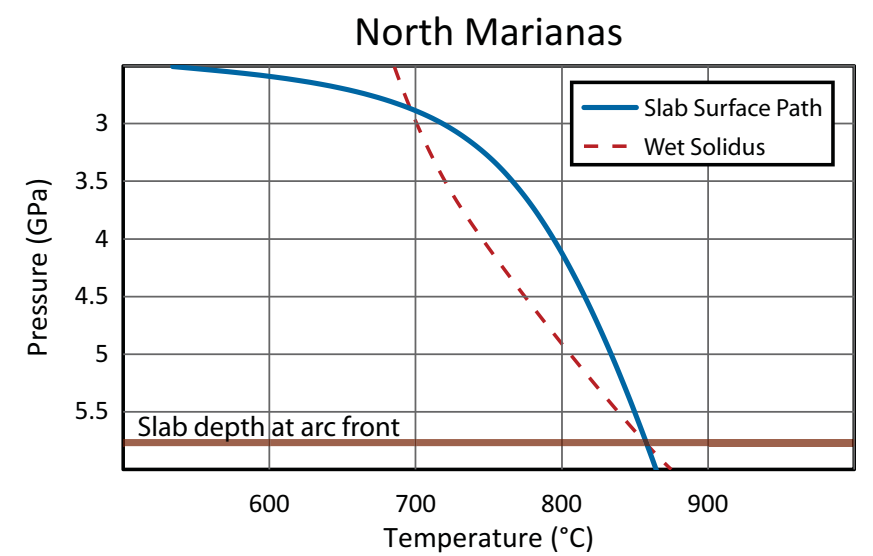

Colombia/Ecuador

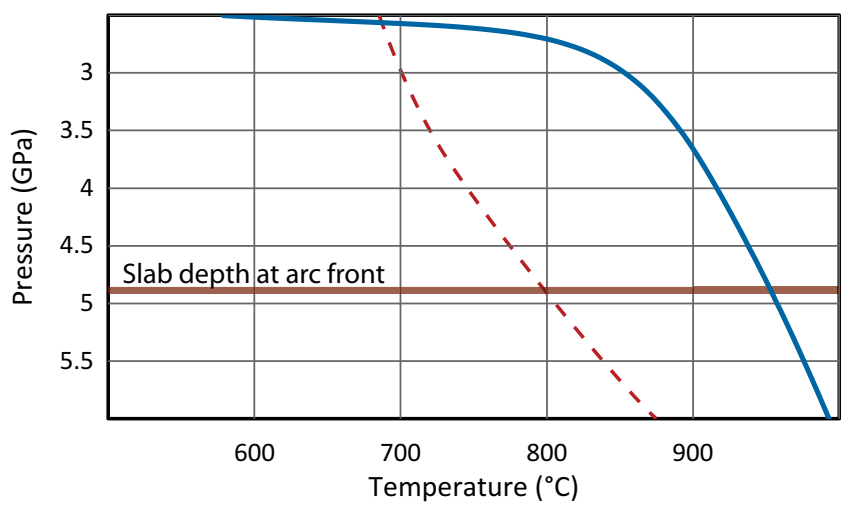

Figure 15. A comparison of the D80 slab surface temperature paths for the North Marianas and Colombia/Ecuador from Syracuse et al. [2010] to the wet slab solidus plotted in Cooper et al. [2012]. Note that the maximum value of $\mathrm{T}_{\mathrm{s}}$ (the distance between the solid blue line and the red dashed line) is reached at much shallower depths than are present below the arc front. If the maximum extent of slab melting is reached well before the arc front, this may account for the lack of a relationship between the subarc slab surface temperatures of Syracuse et al. [2010] and chemical parameters. It would also imply that depth to slab may not be relevant to arc chemical systematics.
Experimental work suggests $\mathrm{Nd}$ does not partition strongly into sediment melts [e.g., Hermann and Rubatto, 2009; Skora and Blundy, 2010], in contrast to elements that are highly mobile or highly abundant in sediments (e.g., $\mathrm{Pb}, \mathrm{Ba}$, Th). Nonetheless, observations such as the correlations between $\mathrm{Th} / \mathrm{Nd}$ and ${ }^{143} \mathrm{Nd} /{ }^{144} \mathrm{Nd}$ in the Marianas [Elliott et al., 1997], or the global relationship between $\mathrm{Nd}_{6.0}$ and ${ }^{143} \mathrm{Nd} /{ }^{144} \mathrm{Nd}$ for most arc segments (Figure 3a), support an important role for sedimentary $\mathrm{Nd}$ in arc volcanics. In this scenario, the covariation of ${ }^{143} \mathrm{Nd} /{ }^{144} \mathrm{Nd}$ and ${ }^{87} \mathrm{Sr} /{ }^{86} \mathrm{Sr}$ among arc front lavas (Figure 2a) could be the result of mixing between depleted mantle and a sediment component with low ${ }^{143} \mathrm{Nd} /{ }^{144} \mathrm{Nd}$ and high ${ }^{87} \mathrm{Sr} /{ }^{86} \mathrm{Sr}$, along with a contribution of $\mathrm{Sr}$ from the altered ocean crust. If this were the case, one might expect a correlation between the thermal parameter and ${ }^{143} \mathrm{Nd} /{ }^{144} \mathrm{Nd}$, because hotter slabs would contribute more of a low ${ }^{143} \mathrm{Nd} /{ }^{144} \mathrm{Nd}$ slab component. No such correlation, however, exists (Figure 7h).

An alternative possibility is that $\mathrm{Nd}$ and $\mathrm{Sr}$ isotope variations reflect a strong imprint from the ambient mantle wedge. This possibility is supported by the correlation of ${ }^{143} \mathrm{Nd} /{ }^{144} \mathrm{Nd}$ between arc front and rear-arc magmas which have been screened for minimal subduction signature (Figure 4b). If true, a significant proportion of Nd in erupted arc magma would be sourced from the ambient mantle wedge, and the correlation between ${ }^{143} \mathrm{Nd} /{ }^{144} \mathrm{Nd}$ and ${ }^{87} \mathrm{Sr} /{ }^{86} \mathrm{Sr}$ in arc front lavas (Figure $2 \mathrm{a}$ ) could originate from the excellent correlation between these isotope systems in the rear-arc (Figure 4a). In this alternate scenario, one would not expect a correlation of ${ }^{143} \mathrm{Nd} /{ }^{144} \mathrm{Nd}$ with either crustal thickness or thermal parameter, consistent with the observations (Figures $7 \mathrm{~g}$ and $7 \mathrm{~h})$.

While there is no relationship between isotopes and the thermal parameter, a major sediment contribution to a potentially heterogeneous mantle wedge is still possible. This would lead to a complex relationship between subducted sediment and arc volcanics, and so the first-order relationships mentioned above do not necessarily rule out an STS model. To assess these possibilities and their significance for the STS and WTS models requires determination of the element and isotope budgets using the sediments appropriate for each subduction zone. The aim is to determine for each of the WTS and STS models what additional constraints are required to satisfy the isotope data.

Forward modeling was undertaken for each of the 11 arcs considered, using the $\mathrm{Sr}$ and $\mathrm{Nd}$ isotope ratios of the filtered rear-arc samples as ambient mantle compositions. Most sediment compositions were taken from the compilation of Plank et al. [2013], though Guatemala and El Salvador were assigned the hemipelagic sediment compositions of Patino et al. [2000]. AOC was assigned ${ }^{87} \mathrm{Sr} /{ }^{86} \mathrm{Sr}$ and ${ }^{143} \mathrm{Nd} /{ }^{144} \mathrm{Nd}$ values of 0.7035 and 0.5131 for all arcs, consistent with average Pacific MORB values for $\mathrm{Nd}$ and altered MORB values 
for Sr [Staudigel et al., 1995]. For both models, the ambient mantle trace element composition was assigned the DMM composition of Workman and Hart [2005] for all arc segments, as an appropriate model relating ambient mantle isotopic variability to trace element compositional variability is still in development. Other model details are identical to those described in section 4 and in the supporting information.

The WTS and STS end-member models are based on separate sets of assumptions concerning the origin of global composition diversity among arcs, and make different predictions about the origin of the isotopic variation. In the WTS model, the global compositional diversity is produced as a function of the wedge thermal structure, while the proportions of slab components are relatively constant. Therefore for this model, AOC and sediment contributions were restricted to the narrow windows of $5-8 \%$ and $0-4 \%$, slab temperature restricted to $825-875^{\circ} \mathrm{C}$, and each arc segment assigned a pressure and temperature of melting based on its crustal thickness. These constraints assure the isotope mass balance is consistent with the WTS model. In this case, much of the isotope variation in ${ }^{143} \mathrm{Nd} /{ }^{144} \mathrm{Nd}$ must be inherited from the mantle wedge.

In the STS model, the global compositional diversity of melt compositions is produced by increasing slab surface temperatures and slab contributions to the mantle wedge, which results from variations in the slab thermal structure while the mantle thermal structure is held fixed. To ensure the isotope mass balance was consistent with the STS model, the extent of mantle wedge melting was constrained between 0.17 and 0.19 at a pressure of $1.8 \mathrm{GPa}$, while slab $\mathrm{T}$ and the proportions of $\mathrm{AOC}$ and sediment melt were allowed to vary from 750 to $950^{\circ} \mathrm{C}, 0 \%$ to $40 \%$, and $0 \%$ to $4 \%$. For the STS model, much of the variation in isotopes must come from changes in the slab component.

To account for crystal fractionation, model results were compared to average 6-values reduced by a factor of 0.9 , (the typical factor evident from plots of incompatible element 6-values versus $\mathrm{Mg} \#>60$ values in TL2015a). Any combination of parameters that produced results within $15 \%$ of average $\mathrm{Nd}, \mathrm{Sr}, 20 \%$ of Dy, and $\mathrm{Yb}$ bulk compositions, within 0.1 of average Dy/Yb values, within .00015 of average ${ }^{143} \mathrm{Nd} /{ }^{144} \mathrm{Nd}$ values and within 0.00025 of average ${ }^{87} \mathrm{Sr} /{ }^{86} \mathrm{Sr}$ values was considered successful. This range of acceptable isotope variation had to be made quite large, as closer matches for Central Chile and Guatemala could not be found in the STS implementation, as discussed below.

For the WTS model, successful solutions were found for each of the arcs considered. The solutions have proportions of $\mathrm{Nd}$ and $\mathrm{Sr}$ from the various source components that are relatively constant across all arcs, despite the variations in subducted sediment compositions (Figure 16). The majority of solutions result in $45-65 \%$ of $\mathrm{Nd}$ contributed from the ambient mantle, 30-40\% from AOC, and 0-20\% from sediment. For Sr, $10-20 \%$ is contributed from the ambient mantle, $60-80 \%$ of $\mathrm{Sr}$ from AOC, and $0-15 \%$ from the sediment. The Central Chile segment extends to higher sediment contributions and lower AOC contributions for Sr.

The STS model also produces successful solutions for most arcs, with worse results for Central Chile and Guatemala. In contrast to the WTS model, however, the proportions of sediment, AOC, and ambient mantle contributions must vary considerably from one arc to another. Proportions of the slab components must increase as the average bulk $\mathrm{Nd}$ and $\mathrm{Sr}$ contents of the arcs increase, seen most readily in the decrease in the proportions from the ambient mantle wedge as the slab temperature goes up (and the thermal parameter decreases) (Figure 17c). For successful solutions, the amount of $\mathrm{Nd}$ from the ambient mantle ranges from $15 \%$ for hot slabs and arcs with high Nd concentrations, to $80 \%$ for cold slabs at depleted arcs. The amount of $\mathrm{Sr}$ from the ambient mantle ranges from $5 \%$ to $30 \%$. Hotter slabs cause the subduction component to increasingly dominate element budgets.

While both WTS and STS models can satisfy the isotope data within the rather loose limits listed above, the conclusions about the sources of elements and the goodness of fit are very different in the two models. For the WTS model, successful runs are found at each arc that give ${ }^{143} \mathrm{Nd} /{ }^{144} \mathrm{Nd}$ within $2 \sigma$ of the arc average. For the STS model, this is not true for Guatemala or Central Chile, for which model results always have ${ }^{143} \mathrm{Nd} /{ }^{144} \mathrm{Nd}$ isotopes higher than those found in the arc. A second caveat for the STS model is that the proportions of the different slab and wedge components do not vary smoothly with thermal parameter (see Figure 17). Kamchatka and South Sandwich, which deviate from the rough monotonic relationship between $\Phi$ and \% $\mathrm{Nd}$ from the ambient mantle, also have some of the largest residuals in a regression of $\Phi$ vs CT.

If the filtered rear-arc data are representative of the ambient mantle wedge compositions, the correlation between arc front and rear-arc Nd isotopes is more plausibly produced by the WTS model. Most successful 


\author{
Wedge Thermal Structure Model
}

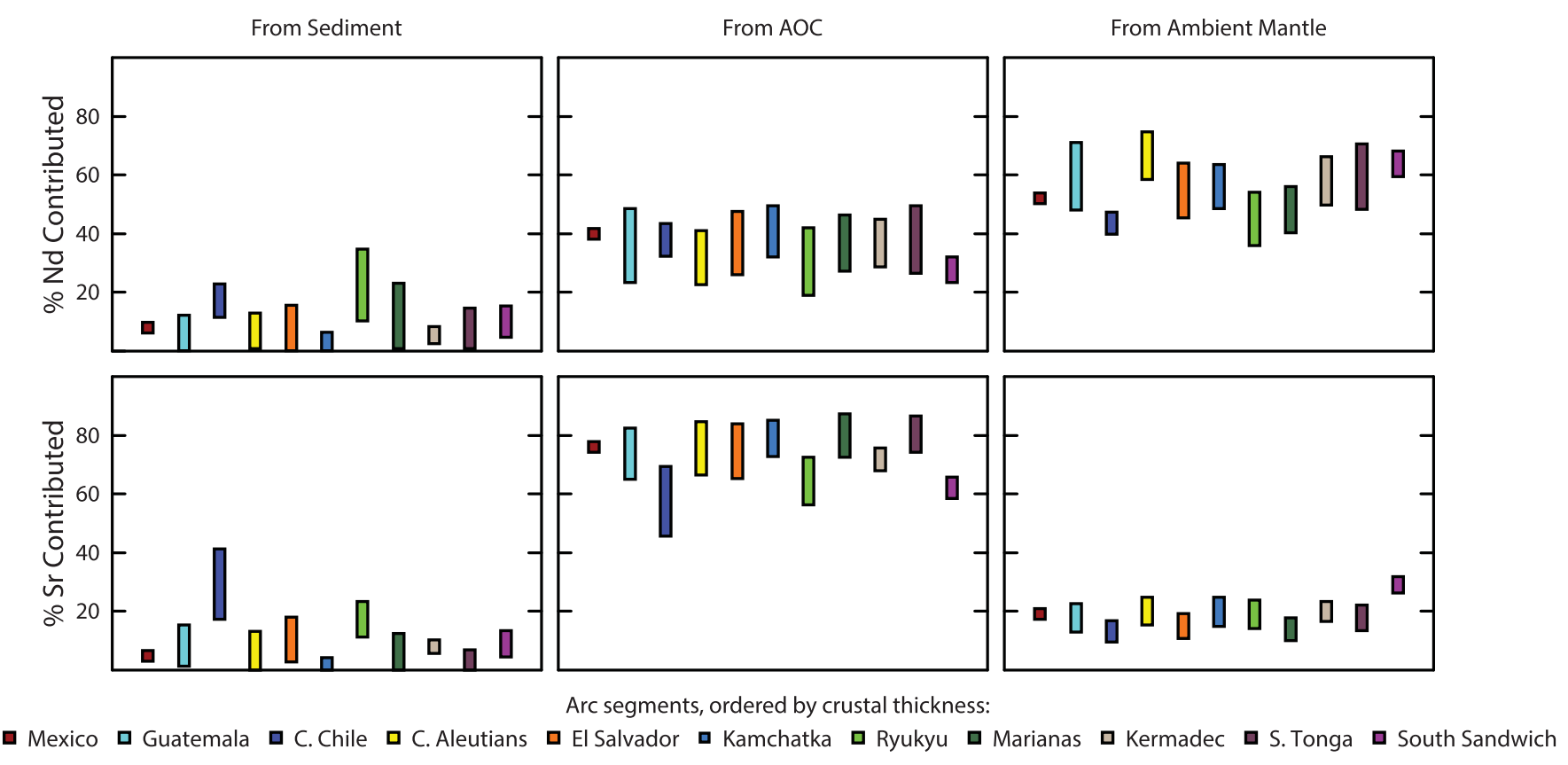

Figure 16. Results of the mass balance modeling for Nd and Sr isotopes discussed in the text for the WTS model. For the 11 arcs with isotope data for the rear-arc and subducting sedi-

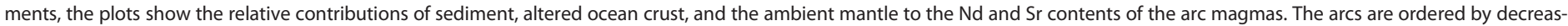
ing crustal thickness from left to right. The figure shows that the isotopes are fit well if the contributions from each source are relatively constant among arc segments. Nd is sourced about $10 \%$ from sediment, $40 \%$ from altered ocean crust, and $50 \%$ from ambient mantle, while Sr is sourced primarily from the altered ocean crust.

runs of the WTS model allow for more than $50 \%$ of arc Nd to be contributed from the ambient mantle wedge, providing an explanation for why the arc front magmas resemble the ambient mantle wedge isotopic values. In the STS model, the fraction of arc Nd derived from the ambient mantle reaches very low proportions, and most of the Nd contributed to mantle melts at enriched arcs comes from either subducting sediment or AOC. In this scenario, a fortuitous balancing act between the enriched sediment and depleted AOC must take place to produce a mantle source that is compositionally similar (for ${ }^{143} \mathrm{Nd} /{ }^{144} \mathrm{Nd}$ values) to the original ambient mantle. Finally, the lack of correlations between subduction parameters and ${ }^{143} \mathrm{Nd} /{ }^{144} \mathrm{Nd}$ does not favor the STS model, as one would expect increasing slab inputs to produce an enhanced sediment signal where slab flux is high, at least among arcs with particularly low ${ }^{143} \mathrm{Nd} /{ }^{144} \mathrm{Nd}$ in their sediment.

The proposal that ${ }^{143} \mathrm{Nd} /{ }^{144} \mathrm{Nd}$ values in arc front magmas reflect the composition of the ambient mantle source also provides simple explanations for the positive correlation between ${ }^{143} \mathrm{Nd} /{ }^{144} \mathrm{Nd}$ and $\mathrm{Ba} / \mathrm{Nb}$ shown in Figure $3 \mathrm{~b}$, and the anticorrelations with $\mathrm{La} / \mathrm{Sm}$ and Th/U, shown in Figures $3 \mathrm{c}$ and $3 \mathrm{~d}$. A depleted wedge will have high ${ }^{143} \mathrm{Nd} /{ }^{144} \mathrm{Nd}$ and low $\mathrm{Ba}$ and $\mathrm{Nb}$ contents, so is easily dominated by the slab component. $\mathrm{Ba} / \mathrm{Nb}$ is little affected by melting, so depleted wedges have the high $\mathrm{Ba} / \mathrm{Nb}$ characteristic of the slab. Depleted wedges also have lower $\mathrm{La} / \mathrm{Sm}$, but the contributions of these elements are less dominated by the slab. Based in Figure $3 \mathrm{~d}$, it may be inferred that slab contributions do not necessarily dominate the Th/U budget of enriched mantle wedges, though partitioning of these elements in slab melts is somewhat less constrained. Variable wedge compositions and constant slab addition therefore account for the anticorrelation between $\mathrm{Ba} / \mathrm{Nb}$ and $\mathrm{La} / \mathrm{Sm}$ (and Th/U) by a straightforward process.

\title{
5. Variable Water Flux and the Potential for Hybrid Models
}

The models described above present plausible mechanisms that can account for the correlations identified in the global arc dataset, but they are not unique solutions, nor are they an exhaustive list of possibilities. 


\section{QAGU Geochemistry, Geophysics, Geosystems}

\section{Slab Thermal Structure Model}
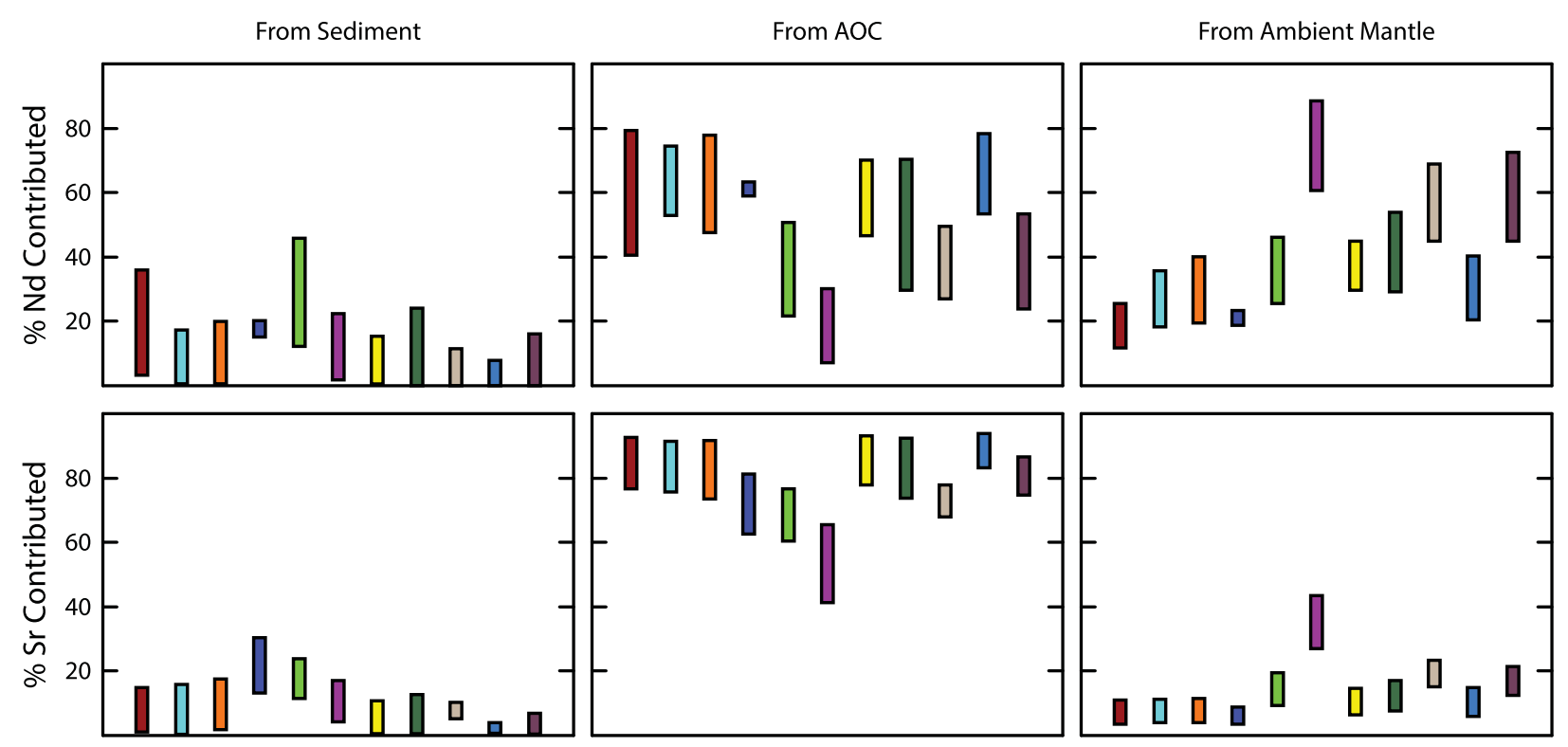

Arc segments, ordered by $\Phi$ :

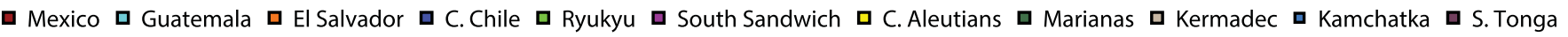

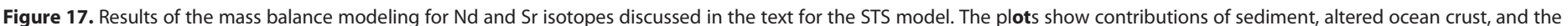

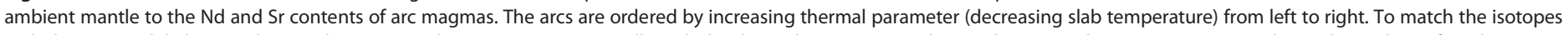

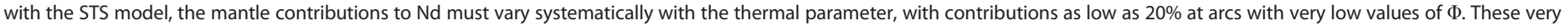

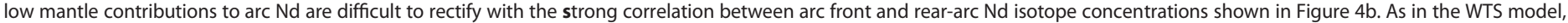
$\mathrm{Sr}$ is primarily derived from the AOC. Note that source proportions are also not a smooth function of thermal parameter. Compare to Figure 16 for the WTS model.

The WTS model, for example, accounts for variable extents of melting in the mantle wedge by changing temperature and pressure. Alternatively, the extent of melting could be predominantly controlled by variation of the mantle's $\mathrm{H}_{2} \mathrm{O}$ contents.

The $\mathrm{H}_{2} \mathrm{O}$ flux from the slab to the mantle may be decoupled from other elemental fluxes if $\mathrm{H}_{2} \mathrm{O}$ is transferred as a low temperature aqueous fluid, which is solute poor. As long as the pressure of melting remains within the garnet stability field, a variable $\mathrm{H}_{2} \mathrm{O}$ flux could lead to results very similar to the WTS model. Several factors could lead to variations in $\mathrm{H}_{2} \mathrm{O}$ delivery to the mantle wedge, including variable initial $\mathrm{H}_{2} \mathrm{O}$ contents in the slab, variable extents of slab dehydration prior to reaching depths relevant to the arc front, and variable extents of slab dehydration beneath the arc front itself.

The hypothesis that the $\mathrm{H}_{2} \mathrm{O}$ flux importantly regulates the extent of mantle melting globally can be tested by using the models of van Keken et al. [2011], which provide estimates of $\mathrm{H}_{2} \mathrm{O}$ flux for different arcs. A high $\mathrm{H}_{2} \mathrm{O}$ flux should produce large extents of melting and low incompatible element abundances. As shown in Figure 18, however, there is no negative correlation between incompatible element abundances (such as $\mathrm{Na}_{2} \mathrm{O}$ ) and $\mathrm{H}_{2} \mathrm{O}$ flux. This would be expected if variable $\mathrm{H}_{2} \mathrm{O}$ was the primary control on $\mathrm{F}$. This result is unsurprising, as the models indicate that only Cascadia, British Colombia, and Mexico should lose significant $\mathrm{H}_{2} \mathrm{O}$ prior to their model's depth of slab-mantle coupling, while the majority of other arcs undergo most dehydration immediately following this depth. This abrupt stepwise change in behavior contrasts with the relatively smooth chemical changes associated with increasing thermal parameter and crustal thickness. Though variable slab dehydration and $\mathrm{H}_{2} \mathrm{O}$ flux from the slab to the mantle likely contribute to some variations in extent of melting at convergent margins, this evidence suggests that that such a process is a second-order effect and does not control the global systematics.

The results of Wilson et al. [2014] provide a possible explanation for why the particular depths of slab dehydration may not determine sub-arc mantle $\mathrm{H}_{2} \mathrm{O}$ contents. Their models show that fluid released over a large range of slab depths may travel up-dip, back toward the arc front. If subducted water is transported mostly 


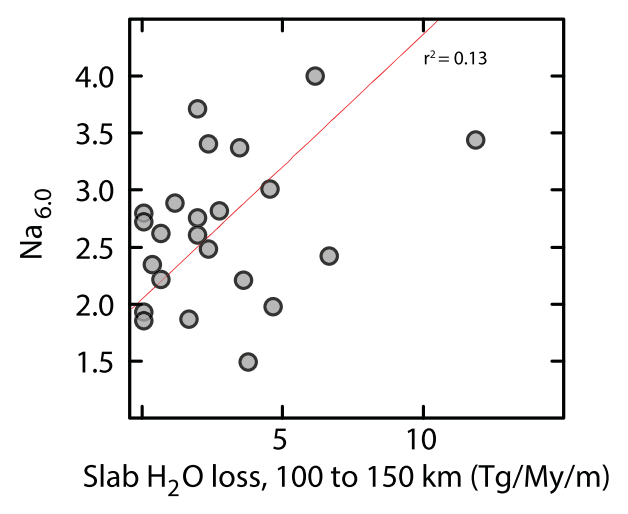

Figure 18. Evaluation of an alternative model where variable extents of melting might be caused by variations in the water flux from the subducting slab. The figure plots $\mathrm{H}_{2} \mathrm{O}$ losses from slab (with serpentinization) from van Keken et al. [2011] against $\mathrm{Na}_{6.0}$. Because increased water should lead to increased extent of melting, an inverse correlation would be predicted. The lack of a relationship between predicted water flux and extent of melting suggests that variable slab dehydration is not the primary control on the extent of mantle melting. within the ocean crust and serpentinized mantle, then the water input is similar among most arcs [van Keken et al., 2011]. Constraints on the quantity of water that can be transported into the deep mantle require that almost all subducted water is released from the slab at shallow depths [Parai and Mukhopadhyay, 2012]. One possible scenario, then, is that large, semiconstant quantities of subducted water are released from the slab over a large range of depths, but are eventually transported to the sub-arc mantle. If true, this would lead to fairly constant water contents in the sub-arc mantle despite highly variable wedge and slab thermal conditions.

Because $\Phi$ and crustal thickness correlate within the dataset, a hybrid model between the WTS model and the STS model may also be possible. Such a model would require, however, a serendipitous combination of covarying factors to produce the correlations between subduction parameters and magma chemistry. It is possible, for example, that the $\mathrm{Dy} / \mathrm{Yb}$ and Sc signals result from variations in modal garnet associated with crustal thickness, while other aspects of magma chemistry are a function of both $\mathrm{F}$ and slab flux. A modeling approach that uses all of these free variables simultaneously is of course possible, though it is not clear what additional constraints this would provide.

\section{Implications for Primary $\mathrm{H}_{2} \mathrm{O}$ and Slab Surface Thermometers}

There are important differences between the mechanisms that these models use to regulate the concentration of $\mathrm{H}_{2} \mathrm{O}$ in primary arc magmas. The WTS model reproduces incompatible element enrichments via changes in the extent of mantle melting driven by variable $\mathrm{P}$ and $\mathrm{T}$ conditions in the mantle wedge. $\mathrm{H}_{2} \mathrm{O}$ behaves like other incompatible elements during mantle melting, and so in this scenario the amount of $\mathrm{H}_{2} \mathrm{O}$ in primary arc magmas should covary with the other incompatible elements. The WTS model reproduces global trends using a constant $0.6 \% \mathrm{H}_{2} \mathrm{O}$ in the mantle source, and thus predicts primary $\mathrm{H}_{2} \mathrm{O}$ concentrations that vary from $\sim 3 \%$ at thin-crust arcs to $\sim 12 \%$ at thick-crust arcs. It is possible to obtain similar results with slightly higher or lower primary water contents by shifting the $\mathrm{P}$ and $\mathrm{T}$ range of melting, but the factor of $\sim 4$ variation in $\mathrm{H}_{2} \mathrm{O}$ contents is a consistent model prediction.

The STS model, on the other hand, requires a relatively constant F in order to reproduce the relatively constant $\mathrm{Yb}$ concentrations. In order to maintain a relatively constant $\mathrm{F}$, the STS model maintains similar $\mathrm{P}$ and T conditions beneath all arcs, and similar $\mathrm{H}_{2} \mathrm{O}$ contents in the mantle wedge. A variable total slab flux with a constant $\mathrm{H}_{2} \mathrm{O}$ flux is possible because any free $\mathrm{H}_{2} \mathrm{O}$ present during slab melting will be incorporated into the melt, and so the total flux of $\mathrm{H}_{2} \mathrm{O}$ to the mantle wedge is not a function of slab surface temperature. Higher extents of slab melting dilute the $\mathrm{H}_{2} \mathrm{O}$ content of slab melts relative to other elements, but the total mass of $\mathrm{H}_{2} \mathrm{O}$ in the slab melt will be constant [Hermann and Rubatto, 2009]. The STS model, therefore, predicts relatively constant $\mathrm{H}_{2} \mathrm{O}$ concentrations in primary melts as concentrations of other slab-mobile elements increase from arcs with a cold slab, to arcs with a hot slab.

In contrast to the WTS and STS models, a slab dehydration model invokes significant variability in the total flux of $\mathrm{H}_{2} \mathrm{O}$ to the mantle wedge. A hot slab, for example, could lose $\mathrm{H}_{2} \mathrm{O}$ prior to reaching depths relevant to arc front volcanism, leaving the mantle wedge above a hot slab less hydrated than a mantle wedge above a cold slab. As discussed in the previous section, such a dehydration model can only be consistent with the global chemical systematics if the cold arc $\mathrm{H}_{2} \mathrm{O}$ flux is transferred as a dilute aqueous fluid. This larger $\mathrm{H}_{2} \mathrm{O}$ flux would produce a greater extent of melting and thus a depleted incompatible element signature at cold, high $\Phi$ arcs. Because arcs with a high $\mathrm{F}$ are then associated with a high $\mathrm{H}_{2} \mathrm{O}$ flux, the primary $\mathrm{H}_{2} \mathrm{O}$ contents of magmas generated by this model are relatively constant. The slab dehydration model is thus similar to the proposal of Plank et al. [2013]: the extent of mantle melting increases roughly 


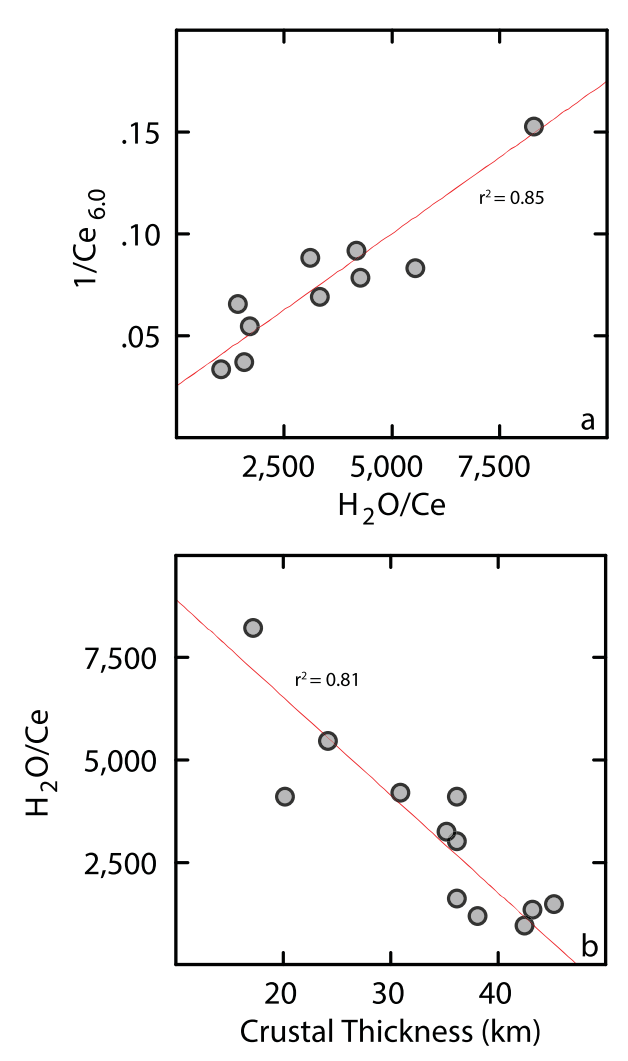

Figure 19. (a) The inverse of $\mathrm{Ce}_{6.0}$ concentrations correlate with the $\mathrm{H}_{2} \mathrm{O} / \mathrm{Ce}$ melt inclusion values from Cooper et al. [2012], showing that $\mathrm{H}_{2} \mathrm{O} / \mathrm{Ce}$ depends primarily on variations in Ce contents. The melt inclusion and $\mathrm{Ce}_{6.0}$ values presented here are in close agreement. (b) While $\mathrm{H}_{2} \mathrm{O} / \mathrm{C}$ ratios of primitive magmas may be generated by the slab, this parameter also correlates well with crustal thickness. The WTS model, however, would not predict this relationship, because both $\mathrm{H}_{2} \mathrm{O}$ and $\mathrm{Ce}$ should vary with extent of melting of the mantle wedge. For the WTS model to be correct, the constant $\mathrm{H}_{2} \mathrm{O}$ contents of melt inclusions must reflect a relatively constant pressure of melt inclusion reequilibration, rather than constant primary water contents.

proportionally to the increase in source $\mathrm{H}_{2} \mathrm{O}$, resulting in fairly constant primary $\mathrm{H}_{2} \mathrm{O}$ concentrations. Plank et al. [2013] propose such a model due to the finding that the average maximum $\mathrm{H}_{2} \mathrm{O}$ contents in melt inclusions, which may represent the primary $\mathrm{H}_{2} \mathrm{O}$ contents of magmas, are similar among all studied arcs. The STS model evaluated here is another mechanism that could produce the same result.

As noted by Plank et al. [2013], the relatively invariant $\mathrm{H}_{2} \mathrm{O}$ contents of arc lava melt inclusions could be due instead to reequilibration of melt inclusions with a surrounding $\mathrm{H}_{2} \mathrm{O}$ saturated magma over a relatively narrow range of crustal depths. This possibility is supported by laboratory dehydration experiments on melt inclusions [Gaetani et al., 2012]. In this case, magmas from thin-crust arcs will have primary water contents of around 3-4 wt \%. These magmas stall in magma chambers at shallow depths of $\sim 6 \mathrm{~km}$, but remain $\mathrm{H}_{2} \mathrm{O}$-undersaturated, and thus melt inclusions formed in thin-crust arcs may reflect their primary $\mathrm{H}_{2} \mathrm{O}$ concentrations. At arcs with $\sim 50 \mathrm{~km}$ crust, on the other hand, the WTS model predicts primary $\mathrm{H}_{2} \mathrm{O}$ contents of around $12 \%$. These magmas most likely stall and differentiate at depths similar to those from thin crust arcs [Blatter et al., 2013; TL2015a], and so are highly $\mathrm{H}_{2} \mathrm{O}$-oversaturated and must degas extensively, eventually reaching $\mathrm{H}_{2} \mathrm{O}$ concentrations similar to primary magmas from thin-crust arcs. Melt inclusions formed in the plumbing systems of thickcrust arcs will then reequilibrate with the degassed magma, which contains 3-4 wt $\% \mathrm{H}_{2} \mathrm{O}$, and thus will not reflect primary $\mathrm{H}_{2} \mathrm{O}$ concentrations. If the melt inclusion $\mathrm{H}_{2} \mathrm{O}$ contents are a result of $\mathrm{H}_{2} \mathrm{O}$ reequilibration following melt inclusion formation, then they will not be directly related to primary magma $\mathrm{H}_{2} \mathrm{O}$ compositions, and thus do not provide direct constraints on global petrogenetic models.

Cooper et al. [2012] suggest that slab surface temperatures predicted by the $\mathrm{H}_{2} \mathrm{O} / \mathrm{Ce}$ contents of melt inclusions, extrapolated from an assumed mantle $\mathrm{Nb} / \mathrm{Ce}$ value, correlate well with the model slab surface temperatures of Syracuse et al. [2010]. If the $\mathrm{H}_{2} \mathrm{O} / \mathrm{Ce}$ values projected from these melt inclusions do represent the slab component, this result appears to provide evidence supporting the STS model, or perhaps a dehydration model, and conflicts with the expected results of the WTS model. In contrast, the dataset of TL2015a shows no strong correlations between magma chemistry and the slab surface temperatures of Syracuse et al. [2010]. This discrepancy is not a consequence of the quality of the datasets used in either study. As shown in Figure 19a, the $\mathrm{H}_{2} \mathrm{O} / \mathrm{Ce}$ melt inclusion data closely correspond to the average $\mathrm{Ce}_{6.0}$ data presented here. Because there is little variation in average melt inclusion $\mathrm{H}_{2} \mathrm{O}$ contents of global arcs [Plank et al., 2013], it is evident that the large variations in the melt inclusion $\mathrm{H}_{2} \mathrm{O} / \mathrm{Ce}$ values are primarily driven by variations in $\mathrm{Ce}$. Thus, the strong correlations between $\mathrm{Ce}_{6.0}$ values and $\mathrm{H}_{2} \mathrm{O} / \mathrm{Ce}$ in melt inclusions support the proposition that both datasets accurately represent variation of $\mathrm{Ce}$ contents in primary arc magmas.

Melt inclusion $\mathrm{H}_{2} \mathrm{O} / \mathrm{Ce}$ ratios not only correlate well with $\mathrm{Ce}_{6.0}$ values, they also independently correlate with crustal thickness, as shown in Figure 19b. If most arc front magmas do in fact undergo crystallization across a narrow range of pressures, and melt inclusions reequilibrate with surrounding $\mathrm{H}_{2} \mathrm{O}$ saturated magmas at these pressures, then the variable Ce contents of melt inclusions are consistent with the WTS model. 
Plank et al. [2013] prefer a model in which melt inclusion $\mathrm{H}_{2} \mathrm{O}$ contents reflect primary magma $\mathrm{H}_{2} \mathrm{O}$ contents, in part because of correlations between $\mathrm{H}_{2} \mathrm{O} / \mathrm{Ce}$ and $\mathrm{Nb} / \mathrm{Ce}$ in the Aleutians. $\mathrm{Nb} / \mathrm{Ce}$ contents of primitive melt inclusions almost certainly represent $\mathrm{Nb} / \mathrm{Ce}$ in primary magmas, and so this argument is compelling. The potential affects of ambient mantle heterogeneity on these ratios within the Aleutians, however, have yet to be investigated. It is also important to realize that the WTS model only requires that melt inclusion $\mathrm{H}_{2} \mathrm{O}$ is reequilibrated with degassed magma chambers at thick-crust, continental arcs. Future experimental work on melt inclusions as well as measurements of multiple chemical indices on melt inclusions from additional subduction settings will likely provide further insight on the relative roles of these subduction parameters in regulating $\mathrm{H}_{2} \mathrm{O}$ and other volatile fluxes through subduction zones.

\section{Conclusions}

A newly compiled global dataset has been used to evaluate relations between subduction parameters and global arc geochemistry. There are remarkably clean relationships among chemical parameters across the entire range of element behavior, and between chemical parameters and the crustal thickness of the overlying arc. Somewhat weaker, but still impressive, correlations exist between the chemical parameters and the slab thermal parameter, which should reflect variations in slab temperature at constant depth. There is also remarkable coherence between $\mathrm{Sr}$ and $\mathrm{Nd}$ isotopic compositions of volcanic front magmas and the compositions of rear-arc magmas that have the least subduction influence. Successful models of arc volcanism should account for these global systematics.

Two distinct end-member models are able to produce the global arc variability. A common feature of both models is that melts of both ocean crust and sediment are required to account for the mass fluxes at convergent margins. This requirement is a consequence of experimental data that show limited solubilities of key elements when the the contribution from the slab is largely fluid, and is consistent with the arguments of Spandler and Pirard [2013]. The wedge thermal structure model calls on a constant flux of sediment and ocean crust melts to a mantle wedge that varies in composition and thermal structure. This model is successful at producing the global observations, and is further supported by the fact that results are improved by including additional parameters that control the wedge thermal structure. This model provides a simple explanation for why Sr, Nb, Zr, K, P, and La all correlate well in global arcs-their relative abundances are controlled largely by extent of melting, while flux from the slab is similar everywhere.

The slab thermal structure model instead invokes a relatively constant extent of melting of the wedge, with a source that varies in composition as a function of slab additions. Flux from the slab varies substantially from one arc to another due to variation in slab temperatures. While successful implementations of this model can be constructed, this model is poorly constrained by experimental data and thermal models. In order to successfully reproduce depletions of $\mathrm{Sc}$ and $\mathrm{V}$, this model requires that significant melt rock reaction takes place in the mantle wedge. A drawback of the model is that results are not improved by incorporating additional subduction parameters that ought to be relevant.

Variations in wedge thermal structure, and hence $\mathrm{T}-\mathrm{T}_{\mathrm{s}}$, at convergent margins are inevitable. Given this fact, a model in which chemical systematics of volcanic arcs are primarily regulated by changing extents of melting is intuitively appealing. Simple thermal models and covariations among elements and subduction parameters are also quantitatively consistent with the variations in extents of melting required to produce the observations. As such, models that include an important role for variations in extent of melting associated largely with lithospheric thickness and convergence rate are strongly supported. An alternative mechanism to produce variable extents of melting would be a globally varying water flux. Quantitative estimates of variations in water flux, however, do not correlate with the extents of melting inferred from arc geochemistry.

It is also true that variations in slab temperature are inevitable, and are quantitatively supported by the maximum depths of earthquakes at subduction zones. It is not necessarily the case, however, that the total chemical flux from the slab will be strongly dependent on slab temperature. Slabs clearly release chemical components to the mantle wedge that are incorporated in arc magmas, but the particular depth at which this happens may be of secondary importance. Slab melting, for example, may initiate well before the volcanic arc front. The top of the slab may also develop into a diapiric mélange and ascend into the core of the mantle wedge, rather than remain stratified and at the base of the wedge [e.g., Marschall and Schumacher, 
2012]. In these cases, flux from the slab to the wedge may be relatively constant across a wide range of thermal parameters. Even in these scenarios, however, the effects of slab temperature may be apparent for the hottest slabs, where slab melting may occur at shallow depths, or where dehydration and chemical transport of particularly mobile elements occur at shallower depths than the convecting mantle wedge.

Two critical parameters that would distinguish between these models are the volumes of magma produced at arcs with a variety of crustal thickness and $\Phi$ values, and firm constraints on the primary water contents of arc magmas from a variety of subduction settings. The WTS model predicts a factor of four variation in water contents, and higher magmatic output at arcs built on thin crust, provided variations in mantle composition are accounted for. The STS model predicts constant water contents and magma volumes. If the WTS model is correct, primary water contents would vary significantly. In this case, the observation that the average arc melt inclusions globally have similar $\mathrm{H}_{2} \mathrm{O}$ contents must be accounted for by the tendency for melt inclusions to reequilibrate with surrounding magmas [Gaetani et al., 2012] within a limited range of depths.

Many models of subduction zones aim to account for the stability and location of volcanic arcs as a result of the breakdown of certain phases in or near the slab [e.g., Grove et al., 2006], or the thermal structure of the mantle wedge [England and Katz, 2010]. The remarkable chemical diversity of arc volcanics provides evidence that either the slab flux, the mantle thermal structure, or both, must be highly variable among arcs. If these parameters determine the location of the arc front, but also must vary from one arc to another, then any model which fully accounts for both wedge geometry and magma chemistry must be highly complex.

It is important to note that the work presented here is not inconsistent with observations regarding the importance of variable sediment compositions for certain elements in global arcs, as demonstrated by Plank and Langmuir [1993]. As shown by that study, the sediment signal emerges only after the effects of varying extents of melting are taken into account, consistent with the WTS model. For the STS model, an evaluation of variations in sediment would need to first take into account the different proportions of subduction components added to the wedge, owing not only sediment volume, composition and convergence rate, but also slab temperature.

Finally, the argument for convergent margin melt production has been presented here with clearly contrasting models, but there must surely be variations in both slab flux and thermal structure for global convergent margins. Further advances in understanding are likely to come from comprehensive studies of individual arcs where subduction parameters vary, rear-arc volcanism constrains the mantle wedge, and geophysics provides constraints on slab and wedge thermal structure. In such a setting, combined geochemical and geophysical models may provide better constraints than are available from a global average study.

\section{Acknowledgments}

This work was supported by NSF grant EAR-0948511. The authors gratefully acknowledge discussions with Mike Dungan, and helpful reviews by Terry Plank and one anonymous reviewer. All data used in this work are either available online via the GEOROC database (http://georoc.mpch-mainz. gwdg.de/georoc/), or in Turner and Langmuir [2015].

\section{References}

Baker, M., M. Hirschmann, M. Ghiorso, and E. Stolper (1995), Compositions of near-solidus peridotite melts from experiments and thermodynamic calculations, Nature, 375, 308-311.

Balta, J. B., P. D. Asimow, and J. L. Mosenfelder (2011), Hydrous, low-carbon melting of garnet peridotite, J. Petrol., 52, $2079-2105$.

Blatter, D. L., T. W. Sisson, and W. B. Hankins (2013), Crystallization of oxidized, moderately hydrous arc basalt at mid-to lower-crustal pressures: Implications for andesite genesis, Contrib. Mineral. Petrol., 166, 861-886.

Cameron, B., J. Walker, M. Carr, L. Patino, O. Matıas, and M. Feigenson (2003), Flux versus decompression melting at stratovolcanoes in southeastern Guatemala, J. Volcanol. Geotherm. Res., 119, 21-50.

Chin, E. J., C.-T. A. Lee, and J. D. Barnes (2014), Thickening, refertilization, and the deep lithosphere filter in continental arcs: Constraints from major and trace elements and oxygen isotopes, Earth Planet. Sci. Lett., 397, 184-200.

Cooper, L. B., D. M. Ruscitto, T. Plank, P. J. Wallace, E. M. Syracuse, and C. E. Manning (2012), Global variations in H ${ }_{2} \mathrm{O} / \mathrm{Ce}$. 1: Slab surface temperatures beneath volcanic arcs, Geochem. Geophys. Geosyst., 13, Q03024, doi:10.1029/2011GC003902.

DePaolo, D. J. (1981), Trace element and isotopic effects of combined wallrock assimilation and fractional crystallization, Earth Planet. Sci. Lett., 53, 189-202.

Elliott, T., T. Plank, A. Zindler, W. White, and B. Bourdon (1997), Element transport from slab to volcanic front at the Mariana arc, J. Geophys. Res., 102, 14,991-15,019.

England, P., R. Engdahl, and W. Thatcher (2004), Systematic variation in the depths of slabs beneath arc volcanoes, Geophys. J. Int., 156, 377-408.

England, P. C., and R. F. Katz (2010), Melting above the anhydrous solidus controls the location of volcanic arcs, Nature, 467, 700-703.

Falloon, T. J., L. V. Danyushevsky, T. J. Crawford, R. Maas, J. D. Woodhead, S. M. Eggins, S. H. Bloomer, D. J. Wright, S. K. Zlobin, and

A. R. Stacey (2007), Multiple mantle plume components involved in the petrogenesis of subduction-related lavas from the northern termination of the Tonga Arc and northern Lau Basin: Evidence from the geochemistry of arc and backarc submarine volcanics, Geochem. Geophys. Geosyst., 8, Q09003, doi:10.1029/2007GC001619. 
Gaetani, G. A., J. A. O'Leary, N. Shimizu, C. E. Bucholz, and M. Newville (2012), Rapid reequilibration of $\mathrm{H}_{2} \mathrm{O}$ and oxygen fugacity in olivinehosted melt inclusions, Geology, 40, 915-918.

Gale, A., C. A. Dalton, C. H. Langmuir, Y. Su, and J. G. Schilling (2013), The mean composition of ocean ridge basalts, Geochem. Geophys. Geosyst., 14, 489-518, doi:10.1029/2012GC004334.

Gazel, E., K. Hoernle, M. J. Carr, C. Herzberg, I. Saginor, P. Van den Bogaard, F. Hauff, M. Feigenson, and C. Swisher (2011), Plume-subduction interaction in southern Central America: Mantle upwelling and slab melting, Lithos, 121, 117-134.

Grove, T. L., N. Chatterjee, S. W. Parman, and E. Médard (2006), The influence of $\mathrm{H}_{2} \mathrm{O}$ on mantle wedge melting, Earth Planet. Sci. Lett., 249, 74-89.

Hermann, J., and D. Rubatto (2009), Accessory phase control on the trace element signature of sediment melts in subduction zones, Chem. Geol., 265, 512-526.

Jaques, A., and D. Green (1980), Anhydrous melting of peridotite at 0-15 kb pressure and the genesis of tholeiitic basalts, Contrib. Mineral. Petrol., 73, 287-310.

Jarrard, R. D. (1986), Relations among subduction parameters, Rev. Geophys., 24, 217-284

Karlstrom, L., C. T. Lee, and M. Manga (2014), The role of magmatically driven lithospheric thickening on arc front migration, Geochem. Geophys. Geosyst., 15, 2655-2675, doi:10.1002/2014GC005355.

Katz, R. F., M. Spiegelman, and C. H. Langmuir (2003), A new parameterization of hydrous mantle melting, Geochem. Geophys. Geosyst., 4(9), 1073, doi:10.1029/2002GC000433.

Kay, R. W. (1980), Volcanic arc magmas: Implications of a melting-mixing model for element recycling in the crust-upper mantle system, J. Geol., 88, 497-522.

Kelley, K. A., T. Plank, L. Farr, J. Ludden, and H. Staudigel (2005), Subduction cycling of U, Th, and Pb, Earth Planet. Sci. Lett., 234, $369-383$.

Kessel, R., M. W. Schmidt, P. Ulmer, and T. Pettke (2005), Trace element signature of subduction-zone fluids, melts and supercritical liquids at $120-180 \mathrm{~km}$ depth, Nature, 437, 724-727.

Kirby, S. H., W. B. Durham, and L. A. Stern (1991), Mantle phase changes and deep-earthquake faulting in subducting lithosphere, Science, 252, 216-225.

Klein, E. M., and C. H. Langmuir (1987), Global correlations of ocean ridge basalt chemistry with axial depth and crustal thickness, J. Geophys. Res., 92, 8089-8115.

Langmuir, C., A. Bézos, S. Escrig, and S. Parman (2006), Chemical systematics and hydrous melting of the mantle in back-arc basins, in Back-Arc Spreading Systems: Geological, Biological, Chemical, and Physical Interactions, Geophys. Monogr. Ser., vol. 166, edited by D. M. Christie et al., pp. 87-146, AGU, Washington, D. C.

Lee, C.-T. A., P. Luffi, T. Plank, H. Dalton, and W. P. Leeman (2009), Constraints on the depths and temperatures of basaltic magma generation on Earth and other terrestrial planets using new thermobarometers for mafic magmas, Earth Planet. Sci. Lett., $279,20-33$.

Marschall, H. R., and J. C. Schumacher (2012), Arc magmas sourced from mélange diapirs in subduction zones, Nat. Geosci., 5 , 862-867.

Miller, D. M., S. L. Goldstein, and C. H. Langmuir (1994), Cerium/lead and lead isotope ratios in arc magmas and the enrichment of lead in the continents, Nature, 368, 514-520.

Montelli, R., G. Nolet, F. Dahlen, and G. Masters (2006), A catalogue of deep mantle plumes: New results from finite-frequency tomography, Geochem. Geophys. Geosyst., 7, Q11007, doi:10.1029/2006GC001248.

Morris, J., and S. Hart (1983), Isotopic and incompatible element constraints on the genesis of island arc volcanics from Cold Bay and Amak Island, Aleutians, and implications for mantle structure, Geochim. Cosmochim. Acta, 47, 2015-2030.

Morris, J., and F. Tera (1989), 10Be and 9Be in mineral separates and whole rocks from volcanic arcs: Implications for sediment subduction, Geochim. Cosmochim. Acta, 53, 3197-3206.

Parai, R., and S. Mukhopadhyay (2012), How large is the subducted water flux? New constraints on mantle regassing rates, Earth Planet. Sci. Lett., 317, 396-406.

Patino, L. C., M. J. Carr, and M. D. Feigenson (2000), Local and regional variations in Central American arc lavas controlled by variations in subducted sediment input. Contributions to Mineralogy and Petrology, 138, 265-283.

Plank, T. (2013), The chemical composition of subducting sediments, in The Crust, Treat. on Geochem., vol. 4, edited by H. D. Holland and K. K. Turekian, pp. 607-629, Elsevier, Oxford, U. K.

Plank, T., and C. H. Langmuir (1988), An evaluation of the global variations in the major element chemistry of arc basalts, Earth Planet. Sci. Lett., 90, 349-370.

Plank, T., and C. H. Langmuir (1993), Tracing trace elements from sediment input to volcanic output at subduction zones, Nature, 362, 739-743.

Plank, T., and C. H. Langmuir (1998), The chemical composition of subducting sediment and its consequences for the crust and mantle, Chem. Geol., 145, 325-394.

Plank, T., L. B. Cooper, and C. E. Manning (2009), Emerging geothermometers for estimating slab surface temperatures, Nat. Geosci., 2, 611-615.

Plank, T., K. A. Kelley, M. M. Zimmer, E. H. Hauri, and P. J. Wallace (2013), Why do mafic arc magmas contain $\sim 4$ wt $\%$ water on average?, Earth Planet. Sci. Lett., 364, 168-179.

Schmidt, M. W., and S. Poli (1998), Experimentally based water budgets for dehydrating slabs and consequences for arc magma generation, Earth Planet. Sci. Lett., 163, 361-379.

Skora, S., and J. Blundy (2010), High-pressure hydrous phase relations of radiolarian clay and implications for the involvement of subducted sediment in arc magmatism, J. Petrol., 51, 2211-2243.

Spandler, C., and C. Pirard (2013), Element recycling from subducting slabs to arc crust: a review, Lithos, 170, $208-223$.

Spandler, C., J. Mavrogenes, and J. Hermann (2007), Experimental constraints on element mobility from subducted sediments using high-P synthetic fluid/melt inclusions, Chem. Geol., 239, 228-249.

Staudigel, H., G. Davies, S. R. Hart, K. Marchant, and B. M. Smith (1995), Large scale isotopic Sr, Nd and O isotopic anatomy of altered oceanic crust: DSDP/ODP sites417/418, Earth Planet. Sci. Lett., 130, 169-185.

Stracke, A. (2012), Earth's heterogeneous mantle: A product of convection-driven interaction between crust and mantle, Chem. Geol., 330 , 274-299.

Straub, S. M., G. F. Zellmer, A. Gómez-Tuena, R. Espinasa-Pereña, A. L. Martin-del Pozzo, F. M. Stuart, and C. H. Langmuir (2013), A genetic link between silicic slab components and calc-alkaline arc volcanism in central Mexico, Geol. Soc. Spec. Publ., 385, 31-64.

Syracuse, E. M., and G. A. Abers (2006), Global compilation of variations in slab depth beneath arc volcanoes and implications, Geochem. Geophys. Geosyst., 7, Q05017, doi:10.1029/2005GC001045.

Syracuse, E. M., P. E. van Keken, and G. A. Abers (2010), The global range of subduction zone thermal models, Phys. Earth Planet. Inter., 183, 73-90. 
Turner, S. J. and C. H. Langmuir (2015), The global chemical systematics of arc front stratovolcanoes: Evaluating the role of crustal processes, Earth and Planet. Sci. Lett., 422, 182-193.

van Keken, P. E., B. R. Hacker, E. M. Syracuse, and G. A. Abers (2011), Subduction factory. 4: Depth-dependent flux of $\mathrm{H}_{2} \mathrm{O}$ from subducting slabs worldwide, J. Geophys. Res., 116, B01401, doi:10.1029/2010JB007922.

Wada, I., and K. Wang (2009), Common depth of slab-mantle decoupling: Reconciling diversity and uniformity of subduction zones, Geochem. Geophys. Geosyst., 10, Q10009, doi:10.1029/2009GC002570.

Willbold, M. and A. Stracke (2006), Trace element composition of mantle end-members: Implications for recycling of oceanic and upper and lower continental crust, Geochem. Geophys. Geosyst., 7, Q04004, doi:10.1029/2005GC001005.

Wilson, C. R., M. Spiegelman, P. E. van Keken, and B. R. Hacker (2014), Fluid flow in subduction zones: The role of solid rheology and compaction pressure, Earth Planet. Sci. Lett., 401, 261-274.

Workman, R. K., and S. R. Hart (2005), Major and trace element composition of the depleted MORB mantle (DMM), Earth Planet. Sci. Lett., 231, 53-72. 